\title{
OPEN L. rhamnosus improves the immune response and tryptophan catabolism in laying hen pullets
}

\author{
Claire Mindus ${ }^{1}$, Nienke van Staaveren ${ }^{1}$, Dietmar Fuchs' ${ }^{2}$, Johanna M. Gostner ${ }^{3}$, \\ Joergen B. Kjaer ${ }^{4}$, Wolfgang Kunze ${ }^{5}$, M. Firoz Mian ${ }^{6}$, Anna K. Shoveller ${ }^{1}$, Paul Forsythe ${ }^{6}$ \& \\ Alexandra Harlander-Matauschek ${ }^{1 \times}$
}

In mammals, early-life probiotic supplementation is a promising tool for preventing unfavourable, gut microbiome-related behavioural, immunological, and aromatic amino acid alterations later in life. In laying hens, feather-pecking behaviour is proposed to be a consequence of gut-brain axis dysregulation. Lactobacillus rhamnosus decreases stress-induced severe feather pecking in adult hens, but whether its effect in pullets is more robust is unknown. Consequently, we investigated whether early-life, oral supplementation with a single Lactobacillus rhamnosus strain can prevent stress-induced feather-pecking behaviour in chickens. To this end, we monitored both the short- and long-term effects of the probiotic supplement on behaviour and related physiological parameters. We hypothesized that $L$. rhamnosus would reduce pecking behaviour by modulating the biological pathways associated with this detrimental behaviour, namely aromatic amino acid turnover linked to neurotransmitter production and stress-related immune responses. We report that stress decreased the proportion of cytotoxic $T$ cells in the tonsils $(P=0.047)$. Counteracting this $T$ cell depression, birds receiving the $L$. rhamnosus supplementation significantly increased all $T$ lymphocyte subset proportions $(\mathrm{P}<0.05)$. Both phenotypic and genotypic feather peckers had lower plasma tryptophan concentrations compared to their non-pecking counterparts. The probiotic supplement caused a short-term increase in plasma tryptophan $(P<0.001)$ and the TRP: $(P H E+T Y R)$ ratio $(P<0.001)$. The administration of stressors did not significantly increase feather pecking in pullets, an observation consistent with the age-dependent onset of pecking behaviour. Despite minimal changes to behaviour, our data demonstrate the impact of $L$. rhamnosus supplementation on the immune system and the turnover of the serotonin precursor tryptophan. Our findings indicate that $L$. rhamnosus exerts a transient, beneficial effect on the immune response and tryptophan catabolism in pullets.

In mammals, the rapid colonization of the gastrointestinal tract (GIT) of newborns by microorganisms is heavily impacted by the mother and the surrounding environment ${ }^{1}$. Impairment of this early-life colonization process can disrupt the microbiota composition of the host ${ }^{2}$ and potentially contribute to diseases and psychological disorders later in life ${ }^{3,4}$. Early-life microbial interventions have been used to prevent dysbiosis-related diseases in adulthood ${ }^{5}$. To this end, Lactobacillus species are among the most important and widely used probiotics in mammals. While lactic acid bacteria are Gram-positive commensals of the GIT, their abundance is low in humans ${ }^{6,7}$. With numerous reported benefits on the stress response, the immune system, and stress-induced behaviour of mammals, Lactobacillus-based treatments are being developed as novel preventives and therapeutics for diseases related to these systems ${ }^{8-11}$.

Similarly, microbial colonization of the chicken GIT plays a key role in immunological and metabolic pathways impacting health and disease ${ }^{12-14}$. The chick gut microbiota undergoes important changes post-hatch ${ }^{14}$. Indeed, the composition and complexity of the gastrointestinal microbial community change rapidly and reach a maximum bacterial density within the first week following hatching ${ }^{15-17}$. In contrast to humans, Lactobacillus is a

\footnotetext{
${ }^{1}$ Department of Animal Biosciences, University of Guelph, 50 Stone Road East, Guelph, ON N1G 2W1, Canada. ${ }^{2}$ Institute of Biological Chemistry, Biocenter, Center for Chemistry and Biomedicine, Medical University of Innsbruck, Innsbruck, Austria. ${ }^{3}$ Institute of Medical Biochemistry, Biocenter, Center for Chemistry and Biomedicine, Medical University of Innsbruck, Innsbruck, Austria. ${ }^{4}$ Institute of Animal Welfare and Animal Husbandry, Friedric h-Loeffler-Institut, Celle, Germany. ${ }^{5}$ Brain-Body Institute, St. Joseph's Healthcare, McMaster University, 1280 Main Street West, Hamilton, ON L8S 4K1, Canada. ${ }^{6}$ Division of Respirology, Department of Medicine, McMaster University, 50 Charlton Avenue East, Hamilton, ON L8N 4A6, Canada. ${ }^{\circledR}$ email: aharland@uoguelph.ca
} 
predominant genus throughout the GIT of chickens, and the commensal lactobacilli become established within the first 7 days following hatch ${ }^{15-18}$. They are found in the crop, the proventriculus, the gizzard, the duodenum, the small intestine, and the ceca ${ }^{14,19-24}$. The intestinal Lactobacillus population likely originates from the established microbiota of the $\mathrm{crop}^{25}$. Lactobacilli resist the low $\mathrm{pH}$ and bile salt encountered in the chicken GIT $^{26}$ allowing them to survive the transit through the stomach and duodenum ${ }^{26}$. As such, Lactobacillus species are interesting candidates for early-life supplementation aimed at shaping the bacterial community in chickens as: (1) they are a prominent genus within the gut which may translate to a greater role in GIT signaling pathways and (2) they can survive the passage through the GIT if introduced as an oral supplement.

Commensal bacteria exert a range of protective structural and metabolic effects on the $\mathrm{GIT}^{27}$. These include nutrient absorption, development of immunity, and competitive exclusion of pathogenic bacteria ${ }^{18,28}$. Indeed, lactobacilli inhibit the growth of pathogens like Campylobacter ${ }^{29}$ and improve the numbers of other beneficial microbes ${ }^{15}$. Lactobacillus spp. also contribute to chicken intestinal homeostasis by exerting immunomodulatory effects $^{30-33}$. For example, they reshape cytokine expression in chicken cecal tonsils ${ }^{30-32}$ and increase T lymphocyte subpopulations in the GIT of stressed and non-stressed chicks ${ }^{33}$. Furthermore, they modulate the catabolic pathway of the aromatic amino acids (AAA), tryptophan (TRP) ${ }^{26,34,35}$, phenylalanine (PHE), and tyrosine $(\mathrm{TYR})^{36}$. Consequently, lactobacilli influence the level of monoamine neurotransmitters ${ }^{37}$ and the production of neurotransmitters in vivo or in-vitro, such as $\mathrm{GABA}^{38}$, serotonin ${ }^{39}$, catecholamines $^{39,40}$, and acetylcholine ${ }^{41,42}$. Alterations to the monoaminergic system by the resident lactobacilli can affect both gut and brain function directly and indirectly.

The metabolic changes associated with inflammatory processes and monoaminergic neurotransmitters play a role in disease $\mathrm{e}^{43}$ and psychological disorders, such as anxiety or depression ${ }^{44-47}$. Lactobacillus reuteri intake improved depressive-like behaviour in mice by reversing the stress-induced decrease of fecal $\mathrm{H}_{2} \mathrm{O}_{2}$ levels and depleting the resident Lactobacillus population ${ }^{35}$. The same treatment also increased intestinal IDO- 1 expression, the primary enzyme responsible for TRP degradation, and increased plasma kynurenine (KYN) levels ${ }^{35}$, an indicator of TRP degradation away from serotonin production. Furthermore, orally administered Lactobacillus rhamnosus reduced stress-induced anxiety- and depression-related behaviour in mice ${ }^{9,48}$. Together, this data suggests that probiotic supplements containing Lactobacillus species can improve behaviour, especially under stress ${ }^{8}$.

Interestingly, Lactobacillus bacteria have also been linked to severe feather pecking (SFP) ${ }^{49-51}$, a damaging behaviour, often characterized as a psychological disorder in birds ${ }^{52,53}$. While gentle feather pecking (GFP) is a normal part of the laying hen's natural social behaviour, severe, excessive and repetitive pecking, pulling, and sometimes eating feathers of conspecifics can lead to feather damage, skin injury, and death ${ }^{54}$. SFP etiology is multifaceted with evidence implicating genetic ${ }^{55-57}$ and environmental components ${ }^{58,59}$. It is proposed to be triggered by chronic, unpredictable social or environmental stressors ${ }^{54}$, but the extent and nature of the stress response may differ across genetic lines ${ }^{60}$.

Regardless of the determinants of SFP behaviour, several important observations indicate the involvement of major signaling pathways and the gut microbiota in its pathophysiology in domestic birds. Indeed, birds bred for their high SFP activity are characterized by a lower relative abundance of Lactobacillus in the cecal feces compared to non-SFP individuals ${ }^{50,51}$. SFP birds also display distinct AAA metabolism, including higher dopamine and serotonin turnover in the brain, both in the absence of stress ${ }^{61}$ and under acute stress ${ }^{62}$. Other studies show low PHE:TYR and KYN:TRP ratios in stressed SFP birds compared to stressed non-SFP counterparts ${ }^{63,64}$. Furthermore, the gene expression patterns of the neuroendocrine, monoaminergic and immune systems of high peckers are distinct from those of low peckers ${ }^{60,65-70}$.

The Lactobacillus genus is significantly underrepresented in the cecal droppings of feather peckers ${ }^{50,51,71}$. Furthermore, L. rhamnosus has been demonstrated to attenuate behavioural deficits induced by chronic social stress in mice ${ }^{72}$. Therefore, we originally postulated that oral supplementation with Lactobacillus rhamnosus may alter SFP behaviour in chickens. Subsequently, we successfully demonstrated that oral supplementation with $L$. rhamnosus JB-1 prevented SFP in adult chickens ${ }^{73}$. We, therefore, hypothesize that the administration of L. rhamnosus to pullets may have a more substantial impact on the microbiota composition. Subsequently, we anticipated changes to stress-induced pecking behaviour, and associated immunological and metabolic changes in laying hens receiving a probiotic supplement. To this end, we investigated whether oral supplementation with the L. rhamnosus JB-1 strain during the first nine weeks post-hatch can be a preventive measure against chronic, repeated, and unpredictable stressors later in life. The impact of Lactobacillus supplementation was measured by quantifying its ability to prevent SFP behaviour, modulate immunological markers and actors (KYN:TRP ratio, nitrite level, and T cells profile) and affect AAA metabolism (TRP, PHE, TYR, and their respective ratios) in birds selected for and against SFP.

\section{Results}

Low severe feather-pecking activity in pullets and adult birds. To assess if Lactobacillus (Lacto) supplementation can prevent stress-induced severe feather pecking (SFP) behaviour and/or increase gentle feather pecking (GFP), a form of positive social interaction, the incidence of SFP and GFP were recorded for all birds. Pecking behaviour was recorded when birds were pullets (10-13 weeks of age [woa]) and adults (32 woa) to measure both the short- and long-term impact of the supplementation.

The descriptive statistics per treatment groups are listed in Supplementary Table S1, and the odds ratio and statistics are presented in Table 1 . The average SFP frequency was $0.051 \pm 0.48$ pecks $/ 10$ min $($ mean \pm SD) in pullets and $0.045 \pm 0.34$ pecks $/ 10 \mathrm{~min}$ in adult birds. On average, $29 \%$ of pullets were classified as gentle feather peckers and $16 \%$ as severe feather peckers, while $2 \%$ of adult birds were classified as gentle feather peckers and $4 \%$ as severe feather peckers. 


\begin{tabular}{|c|c|c|c|c|c|c|c|}
\hline \multirow[b]{2}{*}{ Behaviour } & \multirow[b]{2}{*}{ Treatment } & \multirow[b]{2}{*}{ Class } & \multicolumn{3}{|c|}{ Short term (10-13 woa) } & \multicolumn{2}{|l|}{ Long term (32 woa) } \\
\hline & & & OR & $95 \% \mathrm{CI}$ & P-value & Chi-square statistic & P-value \\
\hline \multirow{4}{*}{ Gentle feather pecking } & \multirow{2}{*}{ Supplementation } & Placebo & Ref & Ref & \multirow{2}{*}{0.235} & \multirow{2}{*}{$\mathrm{X}_{(1, \mathrm{~N}=708)}=0.529$} & \multirow{2}{*}{0.467} \\
\hline & & Lacto & 0.76 & $0.483-1.196$ & & & \\
\hline & \multirow{2}{*}{ Stress } & S & Ref & Ref & \multirow{2}{*}{$<0.001$} & \multirow{2}{*}{$\mathrm{X}_{(1, \mathrm{~N}=708)}=4.551$} & \multirow{2}{*}{0.033} \\
\hline & & NS & 2.57 & $1.632-4.039$ & & & \\
\hline \multirow{4}{*}{ Severe feather pecking } & \multirow{2}{*}{ Supplementation } & Placebo & Ref & Ref & \multirow{2}{*}{0.480} & \multirow{2}{*}{$\mathrm{X}_{(1, \mathrm{~N}=708)}=3.035$} & \multirow{2}{*}{0.082} \\
\hline & & Lacto & 1.31 & $0.62-2.765$ & & & \\
\hline & \multirow{2}{*}{ Stress } & $\mathrm{S}$ & Ref & Ref & \multirow{2}{*}{0.016} & \multirow{2}{*}{$\mathrm{X}_{(1, \mathrm{~N}=708)}=0.542$} & \multirow{2}{*}{0.461} \\
\hline & & NS & 2.52 & $1.194-5.327$ & & & \\
\hline
\end{tabular}

Table 1. Odds Ratio (OR) estimates and 95\% Confidence Interval (CI), and Chi-square statistics of the short-term (between 10 and 13 weeks of age [woa]) and long-term (32 woa) feather-pecking behaviour in laying hens. OR $>1$ indicates that birds are more likely to be classified as a feather pecker, whereas an OR $<1$ indicates that birds were less likely to be classified as a feather pecker (Feather Pecker: bird that displayed gentle or severe feather pecking at least once between $10-13$ woa or 32 woa). Placebo = water supplementation, Lacto $=$ L. rhamnosus, $\mathrm{S}=$ stressed, NS $=$ non-stressed, $\mathrm{Ref}=$ Reference value, $\mathrm{n}$ of birds at 10-13 woa: Placebo $=178$, Lacto $=176, S=177, \mathrm{NS}=177$ and $\mathrm{n}$ of birds at 32 woa: Placebo $=154$, Lacto $=157, \mathrm{~S}=156$, NS $=155$.

We report no interaction between supplementation (Lacto, Placebo) and stress (stress, no-stress) treatments on GFP ( $\mathrm{P}=0.958$ at $10-13$ woa, $\mathrm{P}=0.408$ at 32 woa) or SFP $(\mathrm{P}=0.424$ at $10-13$ woa, $\mathrm{P}=0.309$ at 32 woa). Furthermore, we observed no effect of the supplementation alone in short-term (10-13 woa) or long-term (32 woa) SFP and GFP (Table 1; P > 0.05). The odds ratio (OR) for expressing SFP was significantly higher $(\mathrm{OR}>1$ indicating increased likelihood of expressing the behaviour) in non-stressed pullets compared to stressed pullets (Table 1). Long-term (32 woa) SFP behaviour remained unaltered by the supplement and stress (Table 1). The odds of expressing GFP were also higher in non-stressed pullets (Table 1) compared to their stressed counterparts. This trend held true in the long-term as well; $87.5 \%$ of GFP occurrences in adult birds at 32 woa were observed in the non-stressed group (displayed by only $4 \%$ of the birds). The remaining $12.5 \%$ of the GFP occurrences were observed in the stressed group and were displayed by $1 \%$ of birds (Table 1 ).

In addition to pecking behaviour, integument damage, an overall indicator of a bird's body condition, was evaluated by combining the skin injury score and the feather scores into one integument damage index. We report that integument damage was not affected by the supplement type (mean \pm SD: Lacto $1.2 \pm 1.54$ vs Placebo $1.4 \pm 1.71$ ), by the presence of stressors (mean \pm SD: Non-Stress $1.2 \pm 1.53$ vs Stress $1.4 \pm 1.72$ ) or their interaction $(\mathrm{P}>0.05)$.

Regarding the genetic lines, the OR of expressing GFP $\left(\mathrm{F}_{2,340}=5.43, \mathrm{P}=0.0048\right)$ and SFP $\left(\mathrm{F}_{2,340}=4.60, \mathrm{P}=0.011\right)$ was significantly different between pullets of the two genetic lines. Birds from the high SFP line (HFP) displayed higher odds for both behaviours than low SFP (LFP) birds (GFP: $O R=2.678,95 \% \mathrm{CI}=1.486-4.825, \mathrm{P}=0.003$, SFP: $\mathrm{OR}=4.344,95 \% \mathrm{CI}=1.597-11.820, \mathrm{P}=0.012)$. At 32 woa, GFP did not differ between lines $\left(\mathrm{X}^{2}{ }_{(2, \mathrm{~N}=708)}=0.270\right.$, $\mathrm{P}=0.874$ ). The birds from the HFP line performed $71 \%$ of the total SFP occurrences observed, while $24 \%$ was observed in birds from the unselected control line (UC) and 6\% in the LFP line $\left(\mathrm{X}^{2}{ }_{(2, \mathrm{~N}=708)}=12.116, \mathrm{P}=0.002\right)$.

Impact of Lactobacillus supplementation on the immune system in response to stress. Both stress and psychological disorders, like anxiety and depression, are associated with inflammation ${ }^{74}$. Lactobacilli are known to modulate the immune response and to exert anti-inflammatory activity, by modulating $\mathrm{T}$ lymphocyte profiles, particularly through enhancement of the regulatory $\mathrm{T}$ cell population in the gastrointestinal tract and the spleen, an effect that is more pronounced under stress ${ }^{33,73,75-77}$. The present study assessed the ability of an early-life L. rhamnosus supplement to stimulate the avian immune system when challenged by chronic stress. To this end, the proportions of $\mathrm{T}$ helper lymphocytes $\left(\mathrm{CD} 3^{+} \mathrm{CD} 4^{+} \mathrm{T}\right.$ cell), cytotoxic $\mathrm{T}$ cells $\left(\mathrm{CD} 3^{+} \mathrm{CD} 8^{+} \mathrm{T}\right.$ cell), and regulatory $\mathrm{T}$ cells $\left(\mathrm{CD} 3^{+} \mathrm{CD} 4^{+} \mathrm{CD} 25^{+} \mathrm{T}\right.$ cell) in the cecal tonsils and the spleen were analyzed (Fig. $\left.1 \mathrm{a}-\mathrm{f}\right)$.

The proportion of splenic cytotoxic $\mathrm{T}$ cells was significantly higher in birds receiving the Lacto supplement (Lacto: $22.5 \pm 0.56$ vs Placebo: $18.0 \pm 0.56, \mathrm{~F}_{1,23}=31.92, \mathrm{P}<0.0001$, Fig. $1 \mathrm{~b}$ ), both in the presence and absence of stress. Lacto treatment also elevated the proportions of splenic T helper cells (Lacto: $29 \pm 1.2$ vs Placebo: $26 \pm 1.1, \mathrm{~F}_{1,23}=6.30, \mathrm{P}=0.020$, Fig. $1 \mathrm{a}$ ), and regulatory T cells in both the spleen (Lacto: $19 \pm 1.1$ vs Placebo: $14 \pm 1.0, \mathrm{~F}_{1,23}=18.72, \mathrm{P}<0.001$, Fig. $1 \mathrm{c}$ ) and the cecal tonsils (Lacto: $13.0 \pm 0.75$ vs Placebo: $10.5 \pm 0.71, \mathrm{~F}_{1,23}=8.22$, $\mathrm{P}=0.009$, Fig. 1f). Nevertheless, the regulatory $\mathrm{T}$ cell increase was only statistically significant under stress (Fig. 1 $\mathrm{c}$ and $\mathrm{f}$ ). Animals that experienced stress had a decreased the proportion of cytotoxic $\mathrm{T}$ cells in the tonsils (Stress: $9.5 \pm 1.13$ vs Non-Stress: $11.4 \pm 0.93, \mathrm{~F}_{1,23}=4.41, \mathrm{P}=0.047$, Fig. $\left.1 \mathrm{e}\right)$.

Impact of Lactobacillus supplementation on plasma tryptophan. Severe feather-pecking behaviour is modulated by the neurotransmitters serotonin (5-HT) and dopamine $e^{53,61,63,64,78,79}$. The concentrations of these neurotransmitters in the blood are influenced by the availability of their aromatic amino acids (AAAs) precursors, tryptophan (TRP), tyrosine (TYR) and phenylalanine (PHE) $)^{80,81}$. Here, we investigated the changes to 
Spleen
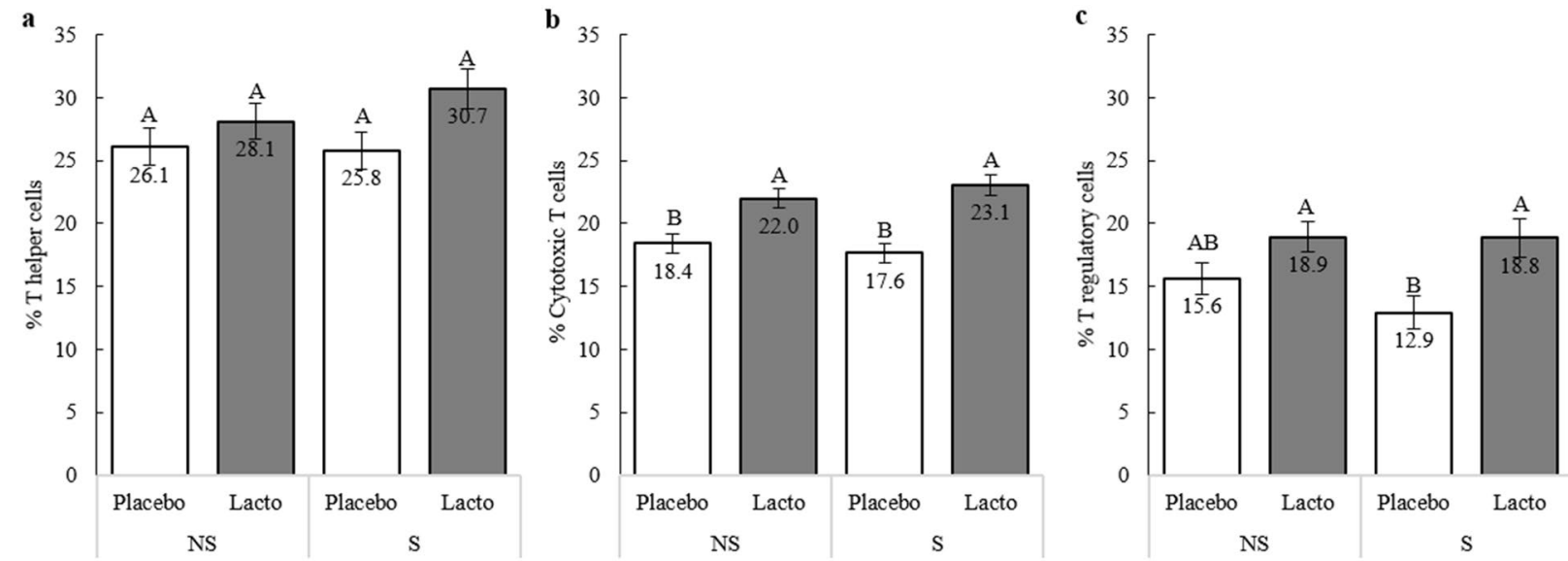

Cecal tonsil
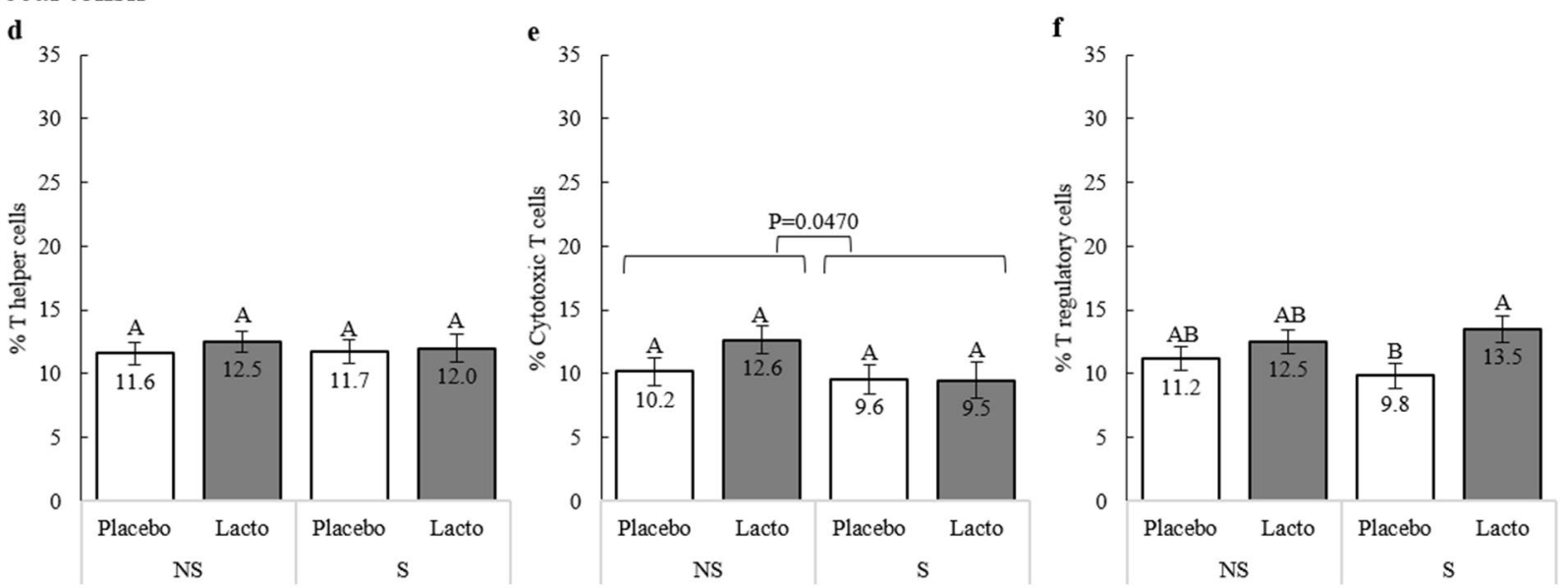

Figure 1. The $\mathrm{T}$ cell sub-populations in the spleen and cecal tonsils. Proportions of $\mathrm{T}$ cell subpopulations in the spleen $(\mathbf{a}-\mathbf{c})$ and cecal tonsil (d-f) after nine weeks of supplementation (0-9 weeks of age) and stress treatment (11-13 weeks of age). Sub-populations were identified using the following combinations of cell surface markers: $\mathrm{T}$ helper cells $=\mathrm{CD} 3^{+} \mathrm{CD} 4^{+}$; cytotoxic $\mathrm{T}$ cells $=\mathrm{CD} 3^{+} \mathrm{CD} 8^{+}$; $\mathrm{T}$ regulatory cells $=\mathrm{CD} 4^{+} \mathrm{CD} 25^{+}(\mathrm{n}$ of birds: S-Placebo $=9$, NS-Placebo $=9$, S-Lacto $=9$, NS-Lacto $=9$, whereby Lacto $=$ L. rhamnosus, Placebo $=$ water supplementation, $\mathrm{S}=$ stressed and NS = non-stressed) in 15 weeks old birds. Different letters indicate statistically significant differences within the Supplementation ${ }^{\star}$ Stress interaction $(\mathrm{P}<0.05)$.

the AAA, KYN and nitrite (immune marker) concentrations in response to Lacto and stress treatment. Changes were monitored at 10,14 and 32 woa (Table 2).

Our results show a significant interaction between supplementation type and time on peripheral plasma TRP concentrations $\left(\mathrm{F}_{2,471}=13.00, \mathrm{P}<0.001\right.$, Table 2$)$ and the TRP: $(\mathrm{PHE}+\mathrm{TYR})$ ratio $\left(\mathrm{F}_{2,474}=14.96, \mathrm{P}<0.001\right.$, Table 2). The latter was used as a proxy for the ratio of total plasma TRP relative to the other large neutral amino acids, an indicator of TRP uptake in the brain and brain 5-HT formation ${ }^{82}$. After 9 weeks of supplementation (10 woa), the Lacto group had higher TRP levels $(+8 \%, \mathrm{P}<0.001$, Table 2$)$ and a higher TRP:(PHE + TYR) ratio $(+9 \%, \mathrm{P}<0.001$, Table 2) compared to the Placebo group. Nevertheless, this effect was not long lasting, as there were no significant differences observed between groups at 14 and 32 woa $(\mathrm{P}>0.05$, Table 2$)$.

We further report that when the data of the three blood collections are pooled (10, 14 \& 32 woa), the supplement type and stress treatment interacted to influence the KYN concentration $\left(\mathrm{F}_{1,469}=8.69, \mathrm{P}=0.003\right)$ and the KYN:TRP ratio $\left(\mathrm{F}_{1,471}=4.11, \mathrm{P}=0.043\right)$. In general, these parameters are more variable in stressed birds. Stressed Lacto birds displayed significantly higher KYN concentrations (Lacto-Stress: $0.315 \pm 0.0071$ vs Placebo-Stress: $0.283 \pm 0.0071, \mathrm{P}=0.007$ ) and a greater KYN:TRP ratio (Lacto-Stress: $3.42 \pm 0.080$ vs Placebo-Stress: $3.20 \pm 0.079$, $\mathrm{P}=0.177$ ) than the stressed Placebo group suggesting that TRP is preferentially directed to the KYN pathway over the 5-HT pathway in stressed birds receiving the Lacto treatment. Lacto supplementation did not significantly alter KYN or the KYN:TRP ratio in the absence of stress. While the interaction between supplementation and stress did not significantly affect the TRP response, the elevated KYN values in stressed Lacto birds are likely a results of elevated plasma TRP concentrations $(\mathrm{P}=0.004)$. However, it is also possible that the observed result is a result of higher IDO-2 enzyme activity ${ }^{63}$. 


\begin{tabular}{|c|c|c|c|c|}
\hline \multirow{2}{*}{$\begin{array}{l}\text { Supplementation } \\
\text { Stress }\end{array}$} & \multicolumn{2}{|l|}{ Lacto } & \multicolumn{2}{|l|}{ Placebo } \\
\hline & Stress $(n=88)$ & Non-stress $(n=88)$ & Stress $(n=89)$ & Non-stress $(n=89)$ \\
\hline \multicolumn{5}{|l|}{10 woa } \\
\hline Tryptophan (TRP) $(\mu \mathrm{mol} / \mathrm{L})$ & $97 \pm 1.1 \mathrm{a}$ & $97 \pm 1.1 \mathrm{a}$ & $90 \pm 1.1 \mathrm{~b}$ & $90 \pm 1.1 \mathrm{~b}$ \\
\hline Tyrosine (TYR) $(\mu \mathrm{mol} / \mathrm{L})$ & $148 \pm 2.5$ & $145 \pm 2.5$ & $152 \pm 2.4$ & $151 \pm 2.5$ \\
\hline Phenylalanine (PHE) $(\mu \mathrm{mol} / \mathrm{L})$ & $95 \pm 1.3$ & $94 \pm 1.3$ & $92 \pm 1.3$ & $98 \pm 1.3$ \\
\hline TRP:(PHE + TYR) & $0.40 \pm 0.006 \mathrm{a}$ & $0.41 \pm 0.006 \mathrm{a}$ & $0.37 \pm 0.006 \mathrm{~b}$ & $0.37 \pm 0.006 \mathrm{~b}$ \\
\hline KYN:TRP $(\mu \mathrm{mol} / \mathrm{mmol})$ & $2.7 \pm 0.13$ & $2.9 \pm 0.13$ & $2.6 \pm 0.13$ & $3.0 \pm 0.13$ \\
\hline PHE:TYR $(\mu \mathrm{mol} / \mu \mathrm{mol})$ & $0.66 \pm 0.011$ & $0.65 \pm 0.011$ & $0.62 \pm 0.011$ & $0.66 \pm 0.011$ \\
\hline Kynurenine $(\mathrm{KYN})(\mu \mathrm{mol} / \mathrm{L})$ & $0.26 \pm 0.012$ & $0.27 \pm 0.012$ & $0.23 \pm 0.012$ & $0.27 \pm 0.012$ \\
\hline Nitrite $(\mu \mathrm{mol} / \mathrm{L})$ & $31 \pm 2.5$ & $36 \pm 2.6$ & $28 \pm 2.5$ & $34 \pm 2.6$ \\
\hline \multicolumn{5}{|l|}{14 woa } \\
\hline Tryptophan (TRP) $(\mu \mathrm{mol} / \mathrm{L})$ & $99 \pm 1.1$ & $98 \pm 1.1$ & $98 \pm 1.1$ & $99 \pm 1.1$ \\
\hline Tyrosine (TYR) $(\mu \mathrm{mol} / \mathrm{L})$ & $160 \pm 2.5$ & $155 \pm 2.5$ & $161 \pm 2.5$ & $154 \pm 2.5$ \\
\hline Phenylalanine (PHE) $(\mu \mathrm{mol} / \mathrm{L})$ & $100 \pm 1.3$ & $98 \pm 1.3$ & $100 \pm 1.3$ & $98 \pm 1.3$ \\
\hline TRP:(PHE + TYR) & $0.39 \pm 0.006$ & $0.39 \pm 0.006$ & $0.38 \pm 0.006$ & $0.40 \pm 0.006$ \\
\hline KYN:TRP $(\mu \mathrm{mol} / \mathrm{mmol})$ & $3.6 \pm 0.13$ & $3.5 \pm 0.13$ & $3.5 \pm 0.13$ & $3.6 \pm 0.13$ \\
\hline PHE:TYR $(\mu \mathrm{mol} / \mu \mathrm{mol})$ & $0.63 \pm 0.011$ & $0.64 \pm 0.011$ & $0.64 \pm 0.011$ & $0.65 \pm 0.011$ \\
\hline Kynurenine $(\mathrm{KYN})(\mu \mathrm{mol} / \mathrm{L})$ & $0.35 \pm 0.012$ & $0.34 \pm 0.012$ & $0.33 \pm 0.012$ & $0.35 \pm 0.012$ \\
\hline Nitrite $(\mu \mathrm{mol} / \mathrm{L})$ & $62 \pm 2.6$ & $61 \pm 2.6$ & $58 \pm 2.6$ & $63 \pm 2.6$ \\
\hline \multicolumn{5}{|l|}{32 woa } \\
\hline Tryptophan (TRP) ( $\mu \mathrm{mol} / \mathrm{L})$ & $81 \pm 1.2$ & $82 \pm 1.2$ & $80 \pm 1.2$ & $81 \pm 1.2$ \\
\hline Tyrosine $(\mathrm{TYR})(\mu \mathrm{mol} / \mathrm{L})$ & $123 \pm 2.6$ & $119 \pm 2.6$ & $119 \pm 2.6$ & $120 \pm 2.7$ \\
\hline Phenylalanine (PHE) $(\mu \mathrm{mol} / \mathrm{L})$ & $105 \pm 1.4$ & $103 \pm 1.4$ & $103 \pm 1.4$ & $101 \pm 1.4$ \\
\hline TRP:(PHE + TYR) & $0.36 \pm 0.006$ & $0.37 \pm 0.006$ & $0.37 \pm 0.006$ & $0.37 \pm 0.006$ \\
\hline KYN:TRP $(\mu \mathrm{mol} / \mathrm{mmol})$ & $4.0 \pm 0.14$ & $3.6 \pm 0.14$ & $3.5 \pm 0.14$ & $3.6 \pm 0.14$ \\
\hline PHE:TYR $(\mu \mathrm{mol} / \mu \mathrm{mol})$ & $0.87 \pm 0.012$ & $0.88 \pm 0.012$ & $0.88 \pm 0.012$ & $0.84 \pm 0.012$ \\
\hline Kynurenine $(\mathrm{KYN})(\mu \mathrm{mol} / \mathrm{L})$ & $0.32 \pm 0.013$ & $0.29 \pm 0.013$ & $0.28 \pm 0.013$ & $0.30 \pm 0.013$ \\
\hline Nitrite $(\mu \mathrm{mol} / \mathrm{L})$ & $77 \pm 2.7$ & $76 \pm 2.7$ & $80 \pm 2.7$ & $72 \pm 2.7$ \\
\hline
\end{tabular}

Table 2. Least Squares Means ( \pm Standard Error) of amino acid concentrations, kynurenine and nitrite (n of birds: S-Placebo $=89$, NS-Placebo $=89, S$-Lacto $=88$, NS-Lacto $=88$ ) at 10, 14 and 32 weeks of age (woa). The birds were submitted to 9 weeks (0-9 woa) of supplementation (Lacto: L. rhamnosus, Placebo: water) and 3 weeks (11-13 woa) of stress treatment (stressed, non-stressed). Different letters indicate statistically significant differences within the same row $(\mathrm{P}<0.05)$.

Changes to plasma tryptophan in genotypic and phenotypic feather peckers. In addition to investigating the impact of the Lacto treatment on AAAs metabolism, we explored the association between the genetic lines and AAAs linked to the kynurenine and dopaminergic pathways at 10, 14, and 32 woa (Table 3). We also examined associations between the pecking phenotype (GFP and SFP behaviour) exhibited by the birds between 10 and 13 woa and the aforementioned metabolic pathways (Table 4).

We found a clear interaction of the genetic line with age in determining the peripheral plasma concentrations of TRP $\left(\mathrm{F}_{4,471}=6.48, \mathrm{P}<0.0001\right.$, Table 3), PHE $\left(\mathrm{F}_{4,473}=2.69, \mathrm{P}=0.031\right.$, Table 3$)$ and TYR $\left(\mathrm{F}_{4,469}=15.31, \mathrm{P}<0.0001\right.$, Table 3$)$, as well as the KYN:TRP ratio $\left(\mathrm{F}_{4,471}=2.66, \mathrm{P}=0.032\right.$, Table 3$)$, the PHE:TYR ratio $\left(\mathrm{F}_{4,465}=4.65, \mathrm{P}=0.001\right.$, Table 3$)$ and the TRP:(PHE + TYR $)$ ratio $\left(F_{4,474}=3.45, P=0.009\right.$, Table 3$)$. Overall, HFP birds had higher TRP:(PHE + TYR) and PHE:TYR ratios and lower plasma TRP, PHE and TYR concentrations than birds from the LFP and UC lines $(\mathrm{P}<0.05)$. It is noteworthy that, these differences were only observed at 10 and 14 woa. Overall, KYN concentrations were lower in the HFP birds compared to the LFP birds $\left(\mathrm{F}_{2,469}=6.85, \mathrm{P}=0.001\right.$, Table 3$)$.

The AAAs, metabolite and nitrite concentrations based on GFP and SFP phenotype is summarized in Table 4. Gentle feather peckers, who exhibited at least one bout of GFP between 10 to 13 woa, had a higher TRP: $(\mathrm{PHE}+\mathrm{TYR})$ ratio $\left(\mathrm{F}_{1,338}=10.11, \mathrm{P}=0.002\right.$, Table 4$)$, a lower TYR concentration $\left(\mathrm{F}_{1,339}=15.35, \mathrm{P}<0.001\right.$, Table 4$)$ and a higher PHE:TYR ratio $\left(\mathrm{F}_{1,338}=10.82, \mathrm{P}=0.001\right.$, Table 4$)$ than birds that did not display this behaviour. On the other hand, birds categorized as severe feather peckers (performing at least one event of SFP between 10 to 13 woa) showed a tendency for lower peripheral plasma TRP $\left(F_{1,338}=3.76, P=0.053\right.$, Table 4$)$ compared to birds that did not perform this behaviour.

\section{Discussion}

The use of Lactobacillus species as a therapeutic for stress-related disorders in humans has gained significant traction over the last decade. In particular, there is an interest in how ingestion of these supplements in childhood or early-life can shape behaviour. The administration of a single Lactobacillus rhamnosus strain successfully 


\begin{tabular}{|c|c|c|c|}
\hline & \multicolumn{3}{|l|}{ Genetic line } \\
\hline & UC $(n=119)$ & LFP $(n=119)$ & HFP $(n=116)$ \\
\hline \multicolumn{4}{|l|}{10 woa } \\
\hline Tryptophan (TRP) $(\mu \mathrm{mol} / \mathrm{L})$ & $94.3 \pm 0.95 \mathrm{a}$ & $98.2 \pm 0.95 \mathrm{a}$ & $88.2 \pm 0.96 \mathrm{~b}$ \\
\hline Tyrosine (TYR) $(\mu \mathrm{mol} / \mathrm{L})$ & $156 \pm 2.1 \mathrm{a}$ & $162 \pm 2.1 \mathrm{ab}$ & $127 \pm 2.1 \mathrm{c}$ \\
\hline Phenylalanine $(\mathrm{PHE})(\mu \mathrm{mol} / \mathrm{L})$ & $97 \pm 1.1 \mathrm{a}$ & $97 \pm 1.2 \mathrm{a}$ & $91 \pm 1.2 \mathrm{~b}$ \\
\hline TRP:(PHE + TYR) & $0.38 \pm 0.005 \mathrm{a}$ & $0.38 \pm 0.005 \mathrm{a}$ & $0.41 \pm 0.005 \mathrm{bc}$ \\
\hline KYN:TRP $(\mu \mathrm{mol} / \mathrm{mmol})$ & $2.6 \pm 0.11 \mathrm{a}$ & $2.9 \pm 0.11 \mathrm{ab}$ & $2.9 \pm 0.12 \mathrm{ab}$ \\
\hline PHE:TYR $(\mu \mathrm{mol} / \mu \mathrm{mol})$ & $0.63 \pm 0.009 \mathrm{a}$ & $0.60 \pm 0.009 \mathrm{a}$ & $0.72 \pm 0.010 \mathrm{~b}$ \\
\hline Kynurenine $(\mathrm{KYN})(\mu \mathrm{mol} / \mathrm{L})$ & $0.25 \pm 0.010 \mathrm{a}$ & $0.28 \pm 0.010 \mathrm{ab}$ & $0.25 \pm 0.010 \mathrm{a}$ \\
\hline Nitrite $(\mu \mathrm{mol} / \mathrm{L})$ & $34 \pm 2.2 \mathrm{a}$ & $33 \pm 2.2 \mathrm{a}$ & $31 \pm 2.2 \mathrm{a}$ \\
\hline \multicolumn{4}{|l|}{14 woa } \\
\hline $\mathrm{TRP}(\mu \mathrm{mol} / \mathrm{L})$ & $96.9 \pm 0.95 \mathrm{a}$ & $103.2 \pm 0.96 \mathrm{c}$ & $96.5 \pm 0.98 \mathrm{a}$ \\
\hline TYR $(\mu \mathrm{mol} / \mathrm{L})$ & $162 \pm 2.1 \mathrm{ab}$ & $170 \pm 2.2 \mathrm{~b}$ & $140 \pm 2.2 \mathrm{~d}$ \\
\hline $\mathrm{PHE}(\mu \mathrm{mol} / \mathrm{L})$ & $100 \pm 1.1 \mathrm{ac}$ & $100 \pm 1.2 \mathrm{ac}$ & $96 \pm 1.2 \mathrm{ab}$ \\
\hline TRP:(PHE + TYR) & $0.37 \pm 0.005 \mathrm{a}$ & $0.39 \pm 0.005 \mathrm{ab}$ & $0.41 \pm 0.005 \mathrm{c}$ \\
\hline KYN:TRP $(\mu \mathrm{mol} / \mathrm{mmol})$ & $3.5 \pm 0.11 \mathrm{c}$ & $3.5 \pm 0.12 \mathrm{c}$ & $3.5 \pm 0.12 c$ \\
\hline PHE:TYR $(\mu \mathrm{mol} / \mu \mathrm{mol})$ & $0.63 \pm 0.009 a$ & $0.59 \pm 0.009 \mathrm{a}$ & $0.69 \pm 0.010 \mathrm{~b}$ \\
\hline $\mathrm{KYN}(\mu \mathrm{mol} / \mathrm{L})$ & $0.34 \pm 0.010 \mathrm{~cd}$ & $0.36 \pm 0.010 \mathrm{c}$ & $0.33 \pm 0.011 \mathrm{~cd}$ \\
\hline Nitrite $(\mu \mathrm{mol} / \mathrm{L})$ & $61 \pm 2.2 \mathrm{~b}$ & $65 \pm 2.2 \mathrm{bc}$ & $57 \pm 2.3 \mathrm{~b}$ \\
\hline \multicolumn{4}{|l|}{32 woa } \\
\hline $\mathrm{TRP}(\mu \mathrm{mol} / \mathrm{L})$ & $80.7 \pm 1.02 \mathrm{~d}$ & $81.9 \pm 1.04 \mathrm{~d}$ & $80.4 \pm 1.05 \mathrm{~d}$ \\
\hline TYR $(\mu \mathrm{mol} / \mathrm{L})$ & $122 \pm 2.3 \mathrm{ce}$ & $123 \pm 2.3 \mathrm{ce}$ & $117 \pm 2.3 \mathrm{e}$ \\
\hline $\mathrm{PHE}(\mu \mathrm{mol} / \mathrm{L})$ & $103 \pm 1.2 \mathrm{c}$ & $103 \pm 1.2 \mathrm{c}$ & $103 \pm 1.2 \mathrm{c}$ \\
\hline TRP:(PHE + TYR) & $0.36 \pm 0.005 \mathrm{a}$ & $0.37 \pm 0.006 \mathrm{a}$ & $0.37 \pm 0.006 \mathrm{a}$ \\
\hline KYN:TRP $(\mu \mathrm{mol} / \mathrm{mmol})$ & $3.8 \pm 0.12 \mathrm{c}$ & $3.8 \pm 0.12 \mathrm{c}$ & $3.4 \pm 0.13 \mathrm{bc}$ \\
\hline PHE:TYR $(\mu \mathrm{mol} / \mu \mathrm{mol})$ & $0.86 \pm 0.010 \mathrm{c}$ & $0.85 \pm 0.010 \mathrm{c}$ & $0.89 \pm 0.010 \mathrm{c}$ \\
\hline $\mathrm{KYN}(\mu \mathrm{mol} / \mathrm{L})$ & $0.31 \pm 0.011 \mathrm{bd}$ & $0.32 \pm 0.011 \mathrm{bcd}$ & $0.27 \pm 0.011 \mathrm{ab}$ \\
\hline Nitrite $(\mu \mathrm{mol} / \mathrm{L})$ & $77 \pm 2.4 \mathrm{~d}$ & $76 \pm 2.4 \mathrm{~d}$ & $75 \pm 2.4 \mathrm{~cd}$ \\
\hline
\end{tabular}

Table 3. Least Squares Means ( \pm Standard Error) of aromatic amino acids, kynurenine and nitrite in birds at 10, 14 and 32 weeks of age (woa) ( $\mathrm{n}$ of birds: $\mathrm{UC}=119, \mathrm{LFP}=119, \mathrm{HFP}=116$, whereby $L F P$ low feather pecking line; HFP high feather pecking line; $U C$ unselected control line). Different letters indicate statistically significant differences across lines within each time point and across time points within each line for each variable $(\mathrm{P}<0.05)$.

prevented severe feather pecking (SFP) in adult laying hens ${ }^{73}$, possibly by restoring the lower abundance of Lactobacillus reported in SFP birds ${ }^{50,51,71}$. In the present study, we evaluate the ability of the same L. rhamnosus strain to act as a preventative measure against SFP when administered in early-life. To this end, pullets received an L. rhamnosus supplement for 9 weeks post-hatch prior to undergoing a stress regimen designed to trigger SFP. In doing so, we aimed to elucidate the potential mechanisms of action through which L. rhamnosus mitigates stress-induced SFP later in life.

We recorded changes to behaviour and physiological parameters in the short-term (weeks 10-14; i.e., pullets), as well as those that manifest later in life (week 32; i.e., adult birds). The impact of L. rhamnosus and stress was measured by quantifying SFP and gentle feather pecking (GFP) behaviour, damage to the feather cover caused by SFP, immunological markers (T cell profiles, KYN:TRP, nitrite) and aromatic amino acid metabolism (tryptophan [TRP], phenylalanine [PHE], tyrosine [TYR], and their ratios). Our data show that early-life $L$. rhamnosus supplementation did not change GFP or SFP frequency and integument damage scores. Overall, $L$. rhamnosus increased the proportions of splenic T helper cells and cytotoxic T cells, as well as splenic and tonsil regulatory $\mathrm{T}$ cells under stress, potentially increasing the capacity of the immune response. Notably, the stress regimen decreased cytotoxic $\mathrm{T}$ cells within the tonsils. Compared to the placebo, the L. rhamnosus supplementation increased peripheral plasma TRP levels and the TRP:(PHE + TYR) ratio in pullets.

Surprisingly, the present study found that the stress treatment did not induce SFP and GFP in pullets. Furthermore, SFP behaviour in pullets and adult birds (Table 1) that received the L. rhamnosus (Lacto) supplement was similar to those receiving the placebo treatment (Placebo). It is noteworthy that SFP outbreaks tend to develop in older flocks ${ }^{83-85}$. Moreover, the SFP frequency observed in the present study in both pullets (mean \pm SD, $0.051 \pm 0.48$ pecks $/ 10 \mathrm{~min}$ ) and adult birds (mean \pm SD, $0.045 \pm 0.34$ pecks $/ 10 \mathrm{~min}$ ) was 6 - to 16 -fold lower than that observed in birds of a similar age and from the same genetic lines in previous studies ${ }^{63,86,87}$. For example, pullets of the high SFP (HFP) line and the low SFP (LFP) line performed in average 0.425 and 0.223 pecks per bird per $10 \mathrm{~min}$, respectively ${ }^{86}$. The low SFP incidence was accompanied by no significant changes to the plumage 


\begin{tabular}{|l|c|c|r|}
\hline & Gentle feather pecker $(\mathbf{n}=\mathbf{1 0 3})$ & Non-gentle feather pecker $(\mathbf{n}=\mathbf{2 5 1})$ & P-value \\
\hline Tryptophan $(\mathrm{TRP})(\mu \mathrm{mol} / \mathrm{L})$ & $99 \pm 1.2$ & $98 \pm 1.0$ & 0.822 \\
\hline Tyrosine $(\mathrm{TYR})(\mu \mathrm{mol} / \mathrm{L})$ & $150 \pm 2.5$ & $161 \pm 1.6$ & $<\mathbf{0 . 0 0 1}$ \\
\hline Phenylalanine $(\mathrm{PHE})(\mu \mathrm{mol} / \mathrm{L})$ & $97.7 \pm 0.94$ & $98.9 \pm 0.62$ & 0.314 \\
\hline TRP:(PHE+TYR) & $0.40 \pm 0.006$ & $0.38 \pm 0.005$ & $\mathbf{0 . 0 0 2}$ \\
\hline KYN:TRP $(\mu \mathrm{mol} / \mathrm{mmol})$ & $3.58 \pm 0.108$ & $3.42 \pm 0.095$ & 0.549 \\
\hline PHE:TYR $(\mu \mathrm{mol} / \mu \mathrm{mol})$ & $0.664 \pm 0.0094$ & $0.627 \pm 0.0061$ & $\mathbf{0 . 0 0 1}$ \\
\hline Kynurenine $(\mathrm{KYN})(\mu \mathrm{mol} / \mathrm{L})$ & $0.35 \pm 0.009$ & $0.36 \pm 0.006$ & 0.441 \\
\hline Nitrite $(\mu \mathrm{mol} / \mathrm{L})$ & $61 \pm 2.3$ & $61 \pm 1.5$ & 0.899 \\
\hline & Severe feather pecker $(\mathbf{n}=56)$ & Non-severe feather pecker $(\mathbf{n}=298)$ & P-value \\
\hline Tryptophan $(\mathrm{TRP})(\mu \mathrm{mol} / \mathrm{L})$ & $96.9 \pm 1.45$ & $98.8 \pm 0.91$ & 0.053 \\
\hline Tyrosine $(\mathrm{TYR})(\mu \mathrm{mol} / \mathrm{L})$ & $155 \pm 3.5$ & $158 \pm 1.5$ & 0.407 \\
\hline Phenylalanine $(\mathrm{PHE})(\mu \mathrm{mol} / \mathrm{L})$ & $98.5 \pm 1.29$ & $98.5 \pm 0.56$ & 0.950 \\
\hline TRP:(PHE $+\mathrm{TYR})$ & $0.38 \pm 0.007$ & $0.390 \pm 0.003$ & 0.367 \\
\hline KYN:TRP $(\mu \mathrm{mol} / \mathrm{mmol})$ & $3.7 \pm 0.14$ & $3.59 \pm 0.086$ & 0.260 \\
\hline PHE:TYR $(\mu \mathrm{mol} / \mu \mathrm{mol})$ & $0.649 \pm 0.0130$ & $0.636 \pm 0.0057$ & 0.356 \\
\hline Kynurenine $(\mathrm{KYN})(\mu \mathrm{mol} / \mathrm{L})$ & $0.35 \pm 0.013$ & $0.35 \pm 0.006$ & 0.918 \\
\hline Nitrite $(\mu \mathrm{mol} / \mathrm{L})$ & $61 \pm 3.2$ & $61 \pm 1.4$ & 0.966 \\
\hline
\end{tabular}

Table 4. Least Squares Means ( \pm Standard Error) of the aromatic amino acids, kynurenine, and nitrite in birds at 14 weeks of age according to their feather pecking phenotype (feather pecker: bird that displayed gentle or severe feather pecking at least once between 10-13 weeks of age).

scores, a reliable indicator of SFP behaviour. It is, therefore, likely that a difference between supplementation groups could not be distinguished due to the low incidence of SFP behaviour observed in the current study.

The stress regimen used to induce SFP in this study was designed to mimic the unpredictable and repeated social and environmental stressors that hens encounter in commercial farm settings ${ }^{88}$. Previous research shows that social disruption alone effectively increases SFP in 16- and 24-weeks old laying hens ${ }^{63,73}$. Surprisingly, we report that the odds of expressing SFP during weeks 10-13 were higher in non-stressed birds compared to the stressed birds (Table 1). Nevertheless, it is noteworthy that these higher odds did not lead to changes in integument damage scores. In contrast, no differences in SFP behaviour were discernible in adult hens at week 32 (Table 1). It is possible that, despite the stressors administered, the housing conditions of the birds in the present study were more enriched than the housing environment of birds in commercial systems. Indeed, a lower frequency of SFP is observed in flocks benefiting from enrichment ${ }^{89}$. Between 10 and 13 woa, the stressed birds had limited access to perches and nest boxes, but these items were not entirely restricted. Furthermore, the social disruption stressor may have been perceived as an enrichment instead of a chronic stress, as it allows young birds to interact with new individuals. Indeed, social hierarchies may not yet be fully established, as birds become more territorial, less adaptable, or more easily frustrated as they age ${ }^{90}$. While the stress regimen consisted of a set of social and environmental stressors, the unexpected positive effect of the former may have compensated for the negative stressors. Consequently, it may have contributed to the decreased expression of SFP in stressed birds and the lack of behavioural difference between the stressed and non-stressed groups at 32 woa. From another perspective, if the social mixing represented a positive event at an early age, the birds may have been inadvertently habituated to social changes and less susceptible to its expected negative effect at 32 woa.

Using a model of chronic stress in laying hen $s^{91}$ and a supplementation protocol proven effective in rodents ${ }^{72}$, we previously demonstrated that continuous ingestion of L. rhamnosus by adult laying hens during a three-week chronic stress treatment reduced $\mathrm{SFP}^{73}$. Taken together with the data presented herein, L. rhamnosus supplementation buffers the effect of stress on SFP behaviour only when administered concomitantly with the stressors. Similar observations have been made with L. rhamnosus JB-1 in a mouse model of chronic social defeat ${ }^{72}$, whereby the probiotic treatment only modulated the behaviour of stressed mice. Therefore, we conclude that a continuous probiotic supplementation would likely be the most effective intervention for stress-induced SFP. Further research is needed to validate if continuous probiotic supplementation in pullets achieves similar results as observed in adult hens.

Despite no significant changes in SFP in response to a preventive probiotic treatment, our data confirm the immunomodulatory effects of L. rhamnosus. Birds receiving the probiotic treatment demonstrated increased expression of cytotoxic and helper T cells in the spleen. Additionally, L. rhamnosus supplementation led to a larger population of regulatory $\mathrm{T}$ (Treg) cells in both the cecal tonsils and the spleen, an effect that was amplified under chronic stress (Fig. 1). Tregs play a fundamental role in the maintenance of immune homeostasis and peripheral tolerance, as well as preventing overwhelming immune responses against invading pathogens. The diversity of the avian gut microbiota affects the complexity of the $\mathrm{T}$ cell receptor repertoire in both the gut and the spleen $^{92}$. Oral administration of some microbial organisms is known to modulate immune responses in the lung, the spleen and cecal tonsils ${ }^{73,76}$. L. reuteri, now re-identified as L. rhamnosus JB- $1^{93}$, induced gut intraepithelial cytotoxic T cells. This effect is proposed to be caused by to the generation of indole derivatives of TRP by the 
bacterium ${ }^{94}$. Thus, we conclude that early-life supplementation with $L$. rhamnosus enhances the local immune system of hens, similarly to previous observations in mice $77,95,96$ and in adult chickens ${ }^{73}$.

Early-life supplementation of L. rhamnosus also increased peripheral TRP concentrations and the TRP:(PHE + TYR) ratio in all birds (Table 2). These results are in accordance with previous data, which suggest that consumption of Lactobacillus bacteria enhances amino acid absorption by increasing amino acid transporters in the small intestinal mucosa ${ }^{97,98}$. Notably, the increase in TRP was only observed immediately after supplementation (10 woa). No difference was observed in the short- (14 woa) and long-term (32 woa). This suggests that the impact of L. rhamnosus treatment is transient. Given that the optimal effect of L. rhamnosus as a probiotic is observed immediately after or during treatment, supplementation appears to be most effective as a curative intervention as opposed to a preventive treatment.

In humans, TRP is mostly catabolized to kynurenine (KYN) by IDO-1, IDO-2 and TDO enzymes. Chickens only possess IDO-2 and TDO but have no gene ortholog for the cytokine-inducible human IDO- ${ }^{99,100}$. A small portion of TRP is also converted to serotonin (5-HT). In parallel, PHE is catabolized to TYR by the PAH enzyme and then, to L-DOPA, the precursor of catecholamines. In humans, the KYN:TRP and PHE:TYR ratios provide an index of IDO-1 and PAH enzyme activities, respectively ${ }^{101,102}$. Both enzymes are regulated by pro-inflammatory stimuli and stress ${ }^{46,103}$. Interestingly, the higher TRP concentration at 10 woa in birds receiving L. rhamnosus was not accompanied by an increased KYN or a higher KYN:TRP ratio. This result contradicts findings in humans, where Alzheimer's disease patients supplemented with Lactobacillus-based probiotics have a significant increase of serum KYN levels, but no change in the concentrations of TRP ${ }^{104}$. Physiological concentrations of TRP and KYN are usually maintained within a relatively narrow range by hepatic tryptophan dioxygenase in mammals ${ }^{105}$. Thus, we hypothesize that the probiotic supplementation increased the TRP concentration, without impacting the KYN pathway. This, in turn, could lead to more TRP being available for 5-HT production, an alternative catabolic pathway ${ }^{106}$ implicated in $\mathrm{SFP}^{53,61,68,70,107}$. Additionally, the transient increase of TRP that is preferentially targeted towards the 5-HT pathway may benefit birds' immune function. In mammals, the IDO-1 enzyme induces an immunosuppressive environment via the degradation of TRP and the accumulation of TRP-derived catabolites (such as KYN), which exert an antiproliferative effect on $\mathrm{T}$ cells ${ }^{108}$. However, birds do not possess IDO- $1^{99}$ and likely use the low efficiency isoenzyme IDO-2. This, in turn, may explain the high TRP, but low KYN levels observed in this study. It also accounts for the enhanced proportions of T cells (Fig. 1); however, this theory requires validation in a bird model.

Birds from the HFP line displayed lower peripheral TRP concentrations at 10 and 14 woa compared to birds from LFP and uncontrolled (UC) lines (Table 3). Moreover, birds categorized as severe feather peckers (phenotype) showed a tendency for lower peripheral plasma TRP than birds that did not perform this behaviour. Taken together, both genotypic and phenotypic SFP correlated with low TRP concentrations. In contrast, pullets classified as gentle feather peckers displayed a higher TRP:(PHE + TYR) ratio, a lower TYR level, and a higher PHE:TYR ratio than birds that displayed no GFP. This contradicts Birkl et al. ${ }^{64}$ who found low PHE:TYR ratios in birds displaying aggressive pecking. Another study found that birds with SFP were characterized by higher PHE and a tendency for higher TYR, than the individuals not expressing the behaviour ${ }^{73}$. It is noteworthy that metabolic pathways linked to the "reward" neurotransmitter dopamine are often involved with SFP behaviour ${ }^{63}$ or aggression ${ }^{64,109}$, whereas GFP is often linked to the serotonergic pathways ${ }^{53,110,111}$. This may partially explain why TRP supplementation failed to modulate SFP in some studies ${ }^{110,112}$.

The data presented herein corroborate previous work that implicate the serotonergic system in the development and modulation of GFP and SFP ${ }^{53,61,68,70,107}$. These studies predominantly suggest that low concentrations of brain 5-HT are associated with a predisposition to perform disruptive pecking behaviour ${ }^{53,113}$. While TRP supplementation is reported to reduce GFP, it failed to attenuate $\mathrm{SFP}^{110}$. Lactobacillus supplementation can be envisaged as a tool to transiently increase TRP concentrations, without the toxicity related to introducing high dietary TRP intake ${ }^{54,112}$. As such, it may be beneficial in birds with a SFP genotype or phenotype.

Finally, some limitations associated with this study must be acknowledged. At 5 woa, the cohort of birds in this study were administered amprolium and penicillin for 6 days to stop the spread of coccidiosis and necrotic enteritis, respectively. The Lactobacillus supplementation was not interrupted during the antiparasitic and antibiotic treatments, continuing for three weeks after its cessation. It is noteworthy that antibiotics dramatically alter the gut microbial composition and contribute to intestinal dysbiosis ${ }^{114,115}$. While some species of lactobacilli have a high intrinsic resistance to some antibiotics ${ }^{116}$, their susceptibility to penicillin varies ${ }^{117,118}$. Specific information on the susceptibility of L. rhamnosus JB-1 to penicillin is currently unavailable. Nevertheless, Simon et al. ${ }^{115}$, showed that dysbiosis induced by a cocktail of antibiotics, including some from the penicillin-type, was remedied two weeks after the end of the treatment. However, we cannot exclude that administering the antibiotic to young birds may have decreased the efficiency of the L. rhamnosus probiotic and/or impacted gastrointestinal tract colonization if the strain used in the study was penicillin-sensitive. We further cannot exclude the possibility that L. rhamnosus ingestion may have prevented or subdued the dysbiosis in response to antibiotic treatment. Another limitation is that the L. rhamnosus supplement was administered in the drinking water to birds as a group, with the exception of hatch day. This methodology was adopted to mimic farming conditions; however, it prevents the calculation of the exact bacterial dose ingested per bird per day. Further work is needed to determine the optimal dosage for L. rhamnosus supplementation. Similarly, individual diet consumption was also not measured. Amino acids concentrations are largely controlled by total dietary intake, and thus, variations in feed consumption may have impacted the observed results.

In conclusion, we supplemented pullets with a daily dosage of L. rhamnosus to study the impact on the development of SFP in stressed laying hens. Following nine weeks of preventive L. rhamnosus supplementation, we observed significant changes to T cell subpopulations and TRP turnover. Nevertheless, the stress treatment did not trigger SFP as intended, which limited our ability to investigate the effects of L. rhamnosus supplementation on SFP directly. However, the data suggest that L. rhamnosus supplementation is most effective in counteracting 
Legend:

Blood collection

Physical examination

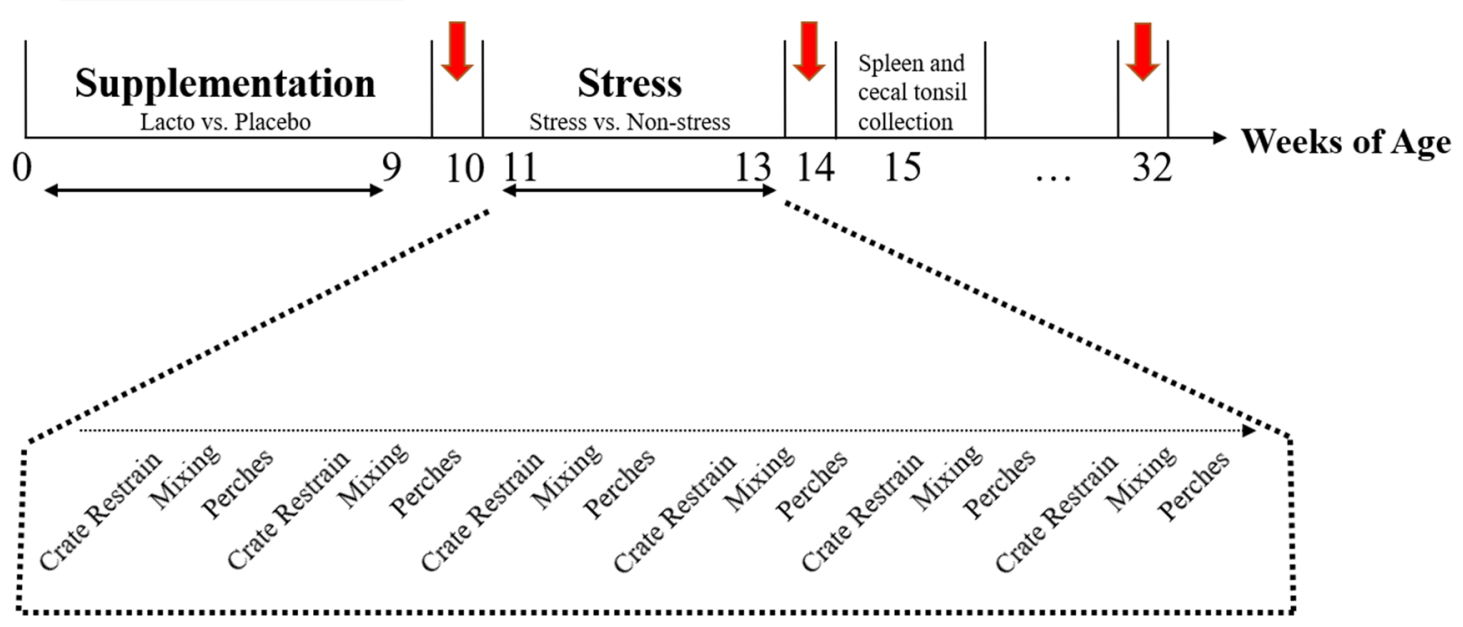

Figure 2. Schematic diagram of the experimental timeline. The Lacto or Placebo supplementation started when birds were 1 day old and lasted 9 weeks. The stress treatment spanned weeks 11-13. Physical examinations and measurements of behaviour, blood samples, and cecal droppings samples were conducted at 10, 14, and 32 weeks of age. Spleen and cecal tonsil samplings were performed at 15 woa from 36 animals.

SFP behaviour when administered during stress rather than preventatively. As such, the stress-dependent beneficial effects of L. rhamnosus is likely due to a buffering effect against stress, via immune system modulation.

\section{Methods}

Ethical statement. This study was approved by the Animal Care Committee at the University of Guelph (Animal Utilization Protocol \#4113). The study was carried out in accordance with relevant guidelines and regulations as well as the ARRIVE guidelines ${ }^{119}$.

Animals and housing. Eggs used in this study originated from White Leghorn laying hens divergently selected for high (HFP) and low (LFP) severe feather pecking (SFP) activity ${ }^{57}$. A third group of eggs from an unselected control (UC) group of White Leghorns were also used. Eggs were incubated together, and birds were hatched and housed under the same conventional management conditions at the Research Station of the University of Guelph in Guelph, Ontario, Canada. On day of hatch, the birds were sexed and individually wing-tagged. A total of 360 non-beak-trimmed females were systematically allocated to 12 pens of 30 birds each (10 birds of each line). The birds were housed in identical floor pens with wood shavings, one round metal feeder $(43 \varnothing \mathrm{cm})$, and a drinker line (7 nipples) in a windowless room. From day 1 until 3 weeks of age (woa), a dark brooder $(98.5 \times 73 \times 39 \mathrm{~cm})$ in which 3 sides were enclosed using white "strip door curtains" (allowing movement in and out while providing darkness) was installed in each pen. Each brooder contained a heating pad. At 4 woa, one A-frame perch $(15 \mathrm{~cm}$ of perch/hen, $55 \mathrm{~cm}$, and $120 \mathrm{~cm}$ above the ground) was added to each pen. At 17 woa, three nest boxes were added to each pen. Opaque PVC boards between the pens prevented birds from seeing each other, and only auditory contact was possible. Light was provided at $20 \mathrm{Lux}$ from 05:00 $\mathrm{h}$ till 19:00 $\mathrm{h}$ and the average daily temperature was $20^{\circ} \mathrm{C}$. Feed and water were provided ad libitum (Research Station feed, Starter: 0 to 6 weeks, Grower: 7 to 16 weeks and Layer: from 17 weeks). The composition and nutrients formulation of the feed are detailed in Supplementary Tables S2 and S3.

At 5 woa, coccidiosis (Eimeria, protozoa) and necrotic enteritis (Clostridium perfringens) caused the death of 4 chicks. The remaining birds were immediately treated with $0.024 \%$ amprolium (Amprol ${ }^{\circ}$, Huvepharma Canada Corporation Inc., Canada) and $0.4 \mathrm{~g} / \mathrm{L}$ penicillin $\mathrm{G}$ potassium (Pot-Pen ${ }^{\oplus}$, Vetoquinol N.-A. Inc., Canada) administered via drinking water for 6 days. At 11 woa, two birds were removed from the experiment due to sexing errors. Between 12 to 14 woa, four birds had to be euthanized for health reasons. At 15 woa, one other bird was euthanized because of cannibalistic pecking injuries.

Lactobacillus rhamnosus supplementation and chronic, unpredictable stress treatments. An overview of the experimental timeline is presented in Fig. 2. Half of the pens were systematically assigned to receive an oral supplement of Lactobacillus rhamnosus JB- $1^{\mathrm{mit}}$ (Lacto, $\mathrm{n}=6$ pens, 176 birds) dissolved in water. The other half received a placebo of drinking water (Placebo, $\mathrm{n}=6$ pens, 178 birds). L. rhamnosus JB-1 was a gift from Alimentary Health Inc., Cork, Ireland to Paul Forsythe and Wolfgang Kunze, McMaster University. To inoculate the bird with a sufficient amount of bacteria once to facilitate colonialization of the gut, on day of hatch, chicks of the Lacto treatment group were individually supplemented with $5 \times 10^{9} \mathrm{CFU}$ of L. rhamnosus JB- ${ }^{\text {tix }}$ dissolved in $0.5 \mathrm{~mL}$ of water, while the Placebo chicks received $0.5 \mathrm{~mL}$ of water, using a $5 \mathrm{~mL}$ plastic syringe. During the 
following 9 weeks, birds were supplemented as a group at the pen level (Monday to Friday, between 9:00 h and 10:30 h). A dose of $5 \times 10^{9} \mathrm{CFU}$ of L. rhamnosus JB-1 per bird was dissolved into drinking water. One hour prior to supplementation, the drinker lines were raised to prevent access, and two round $1 \mathrm{~L}$ drinkers containing either the Lacto or Placebo treatments were placed in the pens. The birds were allowed to voluntarily consume the respective supplement. Individual consumption was not measured. After consumption of the supplements (in approximately 10-15 $\mathrm{min}$ ), the round drinkers were removed from the pens and the regular drinker lines were lowered immediately to allow routine access again.

At 11 woa, a stress regimen was administered to trigger $\mathrm{SFP}^{63}$. Three pens of each supplementation type were randomly assigned to undergo a sequence of stressors spanning a period of 3 weeks ( $\mathrm{s}, \mathrm{n}=6$ pens, 177 birds) while the other three pens were left undisturbed (NS, $n=6$ pens, 177 birds) (Fig. 2). Stressors were environmental (physical restraint of all individuals in a pen for $1 \mathrm{~h}$ in a transport crate and removal of roosting perches for $24 \mathrm{~h}$ ) and social (social disruption by mixing). The stressors used in the present study are reported as potential SFP triggers by previous work ${ }^{63,88,120}$. During social disruption, birds from one pen were divided into two subgroups of 14 to 15 individuals and mixed with another subgroup from a different pen receiving the stress treatment and the same supplement (Lacto or Placebo). Upon mixing, birds were placed in a new but identical pen with fresh shavings to create a new environment for all birds. Each stressor was applied in the afternoon and repeated 5 times. The type of stressor used was balanced over the 3-week period, whereby one stressor was administrated each day between Monday-Friday (Fig. 2). This stress regimen was designed to mimic the unpredictable and repeated stressors that hens encounter in commercial farm settings.

Behavioural observations and physical examinations. Behavioural observations were conducted via video recordings. A camera (Samsung SNO-5080R, IR, Samsung Techwin CO., Gyeongi-do Korea) with an aerial view was installed in each pen. All birds were individually identified using continuously numbered silicone backpacks $(8 \times 6 \times 0.5 \mathrm{~cm})$, fastened around the wings via two elastic straps secured to the backpacks with metal eyelets (Harlander-Matauschek et al., 2009). The time windows used to observe SFP activity were determined by pilot observations. To measure the short-term impact of the supplementation, pens were video recorded for a total of $80 \mathrm{~min}$ during the 3 -weeks stress treatment: $10 \mathrm{~min}$ in the morning for three days spread over the three weeks and 10 min immediately after each mixing stressor. To assess the long-term impact of the supplementation, two more 10-min recordings were made in the morning at 32 woa. Recordings were scheduled outside of the working hours of the farm staff. Behavioural analysis was performed by six blinded observers, trained beforehand (total of $1.7 \mathrm{~h}$ of observations for each of the 354 birds and total of $20 \mathrm{~h}$ of video). Pearson's correlations were calculated for intra $(r=0.8754)$ and inter $(r=0.747)$ observer reliability and were measured through the video observations.

All-occurrence sampling was used to record the actor and the recipient of gentle and severe feather pecking. A sequence of gentle feather pecks $(>4 \mathrm{~s})$ at the tips and edges of feathers of another bird was considered as gentle feather pecking (GFP) ${ }^{64}$, while intent, forceful peck(s) towards the feathers/body of another bird that may remove feathers was considered as severe feather pecking (SFP). Birds exhibiting at least one bout of GFP or one severe feather peck were categorized as gentle, or severe peckers, respectively, for the short- (10-13 woa) and long-term (32 woa). Non-severe peckers and non-gentle peckers were defined as birds that performed 0 bouts or pecks of the respective behaviour.

A physical examination of each individual bird was completed during weeks 10, 14, and 32 (Fig. 2) to determine feather cover, and injuries. The severity of damage to the feather cover on the neck, back, and tail was assessed on a 0 to 3 scale (0: no or slight wear, nearly intact feathering; 1 : damaged feathers or at least one featherless area $<\$ 2$ Canadian coin [diameter of $28 \mathrm{~mm}$ ], 2: at least one featherless area $\geq \$ 2$ Canadian coin and, 3 : at least one featherless area $\geq \$ 2$ Canadian coin with fresh bloodstains) adapted from Decina et al. ${ }^{121}$. Pecking injuries on the comb/head were recorded as present or absent.

Blood sampling and amino acid analysis. At 10, 14, and 32 woa, one-hour post-feeding, blood samples $(2 \mathrm{ml} / \mathrm{hen}$ ) were collected (between 10:00 h and 14:00 h) from the wing vein of each hen into $2 \mathrm{~mL}$ EDTA tubes. The tubes were gently inverted to ensure complete mixing before being stored on ice until the end of sampling (maximum $4 \mathrm{~h}$ ). At the end of sampling, samples were transported $(10 \mathrm{~min})$ to the Department of Animal biosciences of the University of Guelph where the plasma was separated by centrifugation at $4{ }^{\circ} \mathrm{C}, 2,500 \mathrm{rpm}$ for $15 \mathrm{~min}$, and stored at $-80^{\circ} \mathrm{C}$ until further analysis.

The concentrations of amino acids and their derivatives, and nitrite were determined as reported previously as per Mindus et al. ${ }^{73}$. In brief, samples were analysed via reversed-phase HPLC. TRP, PHE and TYR concentrations were determined by monitoring their natural fluorescence at an excitation wavelength of $286 \mathrm{~nm}$ (TRP) and $210 \mathrm{~nm}$ (PHE, TYR), and an emission wavelength of $366 \mathrm{~nm}$ (TRP) and $302 \mathrm{~nm}$ (PHE, TYR). KYN was detected at a wavelength of $360 \mathrm{~nm}$.

In mammals, the KYN:TRP ratio can be used to estimate TRP metabolism along the KYN axis. In humans, this ratio is used as an index of the IDO-1 enzyme-mediated TRP breakdown when accompanied by an increase in markers (such as neopterin) of the cellular immune system ${ }^{101}$. PHE:TYR ratios indicate phenylalanine 4-hydroxylase (PAH) activity, which converts PHE to TYR ${ }^{102}$. TRP:(PHE + TYR) is a substitution for the commonly used ratio of TRP to the large neutral amino acids. As described in Wurtman et al. ${ }^{81}$, this ratio indicates the competition of TRP with other amino acids for uptake across the blood-brain-barrier. As a surrogate marker for nitric oxide (NO) production, the stable NO metabolite nitrite was measured in the plasma sample collected using a modified Griess assay (Merck KGaA, Darmstadt, Germany). 
Flow cytometry analysis for T-lymphocyte profiles. At 16 woa, 36 hens ( 3 hens per line x supplementation type $\mathrm{x}$ stress treatment groups) were killed. Within $3 \mathrm{~min}$ after death, cecal tonsil and spleen tissues were collected from each bird in $5 \mathrm{~mL}$ of RPMI medium containing $5 \%$ fetal bovine serum (FBS) in $15 \mathrm{~mL}$ falcon tubes and kept on ice. Cells from both tissues were isolated, suspended, centrifuged, and counted as per Mindus et al., ${ }^{73}$. Viable spleen and cecal tonsils cells were diluted in Fluorescence-Activated Cell sorting (FACS) buffer (PBS $+2 \%$ FBS) to a concentration of $10^{6}$ cells $/ \mathrm{ml}$. Both splenocytes and cecal tonsil cells were stained for $\mathrm{T}$-helper cell $\left(\mathrm{CD}^{+}{ }^{+} \mathrm{CD} 4^{+} \mathrm{T}\right.$ cell), cytotoxic $\mathrm{T}$ lymphocyte $\left(\mathrm{CD} 3^{+} \mathrm{CD} 8^{+} \mathrm{T}\right.$ cell) and regulatory $\mathrm{T}$ cell $\left(\mathrm{CD} 4^{+} \mathrm{CD} 25^{+}\right.$ T cells) markers using the same antibodies as in Mindus et al. ${ }^{73}$. Data were acquired using FACSCelesta (Becton Dickinson, Oakville, ON, Canada) and analysed by FlowJo (BD Bioscience, Ashland, OR, USA). The gating strategy followed the protocol used in Mindus et al. ${ }^{73}$.

Statistical analysis. Frequencies of behaviours were determined per individual per $10 \mathrm{~min}$. Due to the low frequency of pecking, the behavioural data was analyzed using a binary scale depending on whether or not birds had performed the behaviour in the short- (10-13 woa) or long-term (32 woa) within the course of the experiment. Similarly, the neck, back and tail feather cover scores and the comb injury scores were combined into a new index titled integument damage which reflected presence (at least one score $>0$ ) or absence (all regions scored 0 ) of damage. To further identify the physiological pathways linked to the behaviour, we categorized birds as gentle feather peckers or severe feather peckers based on whether or not they performed the behaviour between weeks 10 to 13 .

Generalized linear mixed models were used to analyze the data collected during this experiment. Variance of GFP and SFP on the short term (weeks 10-13) was partitioned into the fixed effect of Supplementation (Lacto, Placebo), Stress (Stress, Non-Stress), Line (HFP, LFP, UC), and their interaction with a binary distribution. The interaction between the number of birds in a pen at each observation time point and the day of observation was designated as a random effect in the behaviour analysis, with the birds being an experimental unit. Because of zero-biased data, a chi-square test of independence was performed to examine the relation between GFP and SFP displayed over the long term (week 32) and the supplementation, stress, and line. Similarly, variance of the integument damage was partitioned into the fixed effect of supplementation, stress, and line, week of collection $(10,14$ and 32$)$ and their interaction with a binary distribution.

Variance of each T-cell subset was partitioned into the fixed effect of supplementation, stress, line, and their interaction using a normal distribution. Pen of the bird was included as a random effect.

Variance of each aromatic amino acid (AAA), their metabolites, and ratios was partitioned into the fixed effect of supplementation, stress, line, week of collection $(10,14$ and 32) and their interaction with a normal distribution. In the model analyzing the AAA, metabolites and ratios, the pens of the birds were designated as a random effect with the birds classified as an experimental unit and the three collection times were considered as repeated measures. To identify whether AAA were interrelated with pecking behaviour, an additional generalized linear mixed model was performed for each AAA, their metabolites and ratios obtained at 14 woa with the behavioural phenotype displayed from week 10 to 13 as a fixed effect and the pen as a random effect.

All statistical analyses were performed in SAS (Windows version 9.4, SAS Institute, Cary NC). Least squares means and standard errors on the data scale were obtained using the ILINK option. Differences between means were compared pairwise using a Tukey-Kramer adjustment. Scatter plots of studentized residuals against predicted values and treatment values and a Shapiro-Wilk test of normality were used to confirm the assumptions of the variance analysis. To detect possible outliers, studentized residuals outside $a \pm 3.4$ envelope were used. A type I error rate of 0.05 was applied for all statistical tests.

\section{Data availability}

The datasets generated during and/or analysed during the current study are available from the corresponding author on reasonable request.

Received: 9 June 2021; Accepted: 30 August 2021

Published online: 01 October 2021

\section{References}

1. Dominguez-Bello, M. G. et al. Delivery mode shapes the acquisition and structure of the initial microbiota across multiple body habitats in newborns. Proc. Natl. Acad. Sci. U. S. A. 107, 11971-11975 (2010).

2. Shao, Y. et al. Stunted microbiota and opportunistic pathogen colonization in caesarean-section birth. Nature 574, 117-121 (2019).

3. Tamburini, S., Shen, N., Wu, H. C. \& Clemente, J. C. The microbiome in early life: Implications for health outcomes. Nat. Med. 22, 713-722 (2016).

4. Cryan, J. F. \& Dinan, T. G. Mind-altering microorganisms: The impact of the gut microbiota on brain and behaviour. Nat. Rev. Neurosci. 13, 701-712 (2012).

5. Hashemi, A., Villa, C. R. \& Comelli, E. M. Probiotics in early life: A preventative and treatment approach. Food Funct. 7, 1752-1768 (2016).

6. Almonacid, D. E. et al. $16 \mathrm{~S}$ rRNA gene sequencing and healthy reference ranges for 28 clinically relevant microbial taxa from the human gut microbiome. PLOS ONE 12, e0176555 (2017).

7. Nistal, E. et al. Study of duodenal bacterial communities by $16 \mathrm{~S}$ rRNA gene analysis in adults with active celiac disease $v s$ nonceliac disease controls. J. Appl. Microbiol. 120, 1691-1700 (2016).

8. Mindus, C., Ellis, J., van Staaveren, N. \& Harlander-Matauschek, A. Lactobacillus-based probiotics reduce the adverse effects of stress in rodents: A meta-analysis. Front. Behav. Neurosci. 15, 642757 (2021).

9. Bravo, J. A. et al. Ingestion of Lactobacillus strain regulates emotional behavior and central GABA receptor expression in a mouse via the vagus nerve. Proc. Natl. Acad. Sci. USA 108, 16050-16055 (2011). 
10. Palomar, M. M. M. et al. Influence of a probiotic lactobacillus strain on the intestinal ecosystem in a stress model mouse. Brain. Behav. Immun. 35, 77-85 (2014).

11. Huang, R., Wang, K. \& Hu, J. Effect of probiotics on depression: A systematic review and meta-analysis of randomized controlled trials. Nutrients 8, 483 (2016).

12. Varmuzova, K. et al. Composition of gut microbiota influences resistance of newly hatched chickens to Salmonella enteritidis infection. Front. Microbiol. 7, 957 (2016).

13. Brisbin, J. T., Gong, J. \& Sharif, S. Interactions between commensal bacteria and the gut-associated immune system of the chicken. Anim. Health Res. Rev. 9, 101-110 (2008).

14. Stanley, D., Hughes, R. J. \& Moore, R. J. Microbiota of the chicken gastrointestinal tract: Influence on health, productivity and disease. Appl. Microbiol. Biotechnol. 98, 4301-4310 (2014).

15. Ballou, A. L. et al. Development of the chick microbiome: How early exposure influences future microbial diversity. Front. Vet. Sci. 3, 1-12 (2016).

16. Apajalahti, J., Kettunen, A. \& Graham, H. Characteristics of the gastrointestinal microbial communities, with special reference to the chicken. Worlds. Poult. Sci. J. 60, 223-232 (2004).

17. Apajalahti, J. \& Kettunen, A. Microbes of the chicken gastrointestinal tract. In Avian Gut Function in Health and Disease (ed. Perry, G. C.) 124-137 (CAB International, 2006).

18. Tannock, G. W. Minireviews A special fondness for Lactobacilli. Appl. Environ. Microbiol. 70, 3189-3194 (2004).

19. Rehman, H. U., Vahjen, W., Awad, W. A. \& Zentek, J. Indigenous bacteria and bacterial metabolic products in the gastrointestinal tract of broiler chickens. Arch. Anim. Nutr. 61, 319-335 (2007).

20. Van Der Wielen, P. W. J. J., Keuzenkamp, D. A., Lipman, L. J. A., Van Knapen, F. \& Biesterveld, S. Spatial and temporal variation of the intestinal bacterial community in commercially raised broiler chickens during growth. Microb. Ecol. 44, 286-293 (2002).

21. Oakley, B. B. et al. The chicken gastrointestinal microbiome. FEMS Microbiol. Lett. 360, 100-112 (2014).

22. Pan, D. \& Yu, Z. Intestinal microbiome of poultry and its interaction with host and diet. Gut Microbes 5, 108 (2013).

23. Waite, D. W. \& Taylor, M. W. Characterizing the avian gut microbiota: Membership, driving influences, and potential function. Front. Microbiol. 5, 223 (2014).

24. Shang, Y., Kumar, S., Oakley, B. \& Kim, W. K. Chicken gut microbiota: Importance and detection technology. Front. Vet. Sci. 5, 254 (2018).

25. Walter, J. Ecological role of lactobacilli in the gastrointestinal tract: Implications for fundamental and biomedical research. Appl. Environ. Microbiol. 74, 4985-4996 (2008).

26. Dec, M., Nowaczek, A., Urban-Chmiel, R., Stępień-Pyśniak, D. \& Wernicki, A. Probiotic potential of Lactobacillus isolates of chicken origin with anti-Campylobacter activity. J. Vet. Med. Sci. 80, 1195-1203 (2018).

27. O'Hara, A. M. \& Shanahan, F. The gut flora as a forgotten organ. EMBO Rep. 7, 688-693 (2006).

28. Yegani, M. \& Korver, D. R. Factors affecting intestinal health in poultry. Poult. Sci. 87, 2052-2063 (2008).

29. Kizerwetter-Świda, M. \& Binek, M. Protective effect of potentially probiotic Lactobacillus strain on infection with pathogenic bacteria in chickens. Pol. J. Vet. Sci. 12, 15-20 (2009).

30. Haghighi, H. R., Abdul-Careem, M. F., Dara, R. A., Chambers, J. R. \& Sharif, S. Cytokine gene expression in chicken cecal tonsils following treatment with probiotics and Salmonella infection. Vet. Microbiol. 126, 225-233 (2008).

31. Brisbin, J. T. et al. Oral treatment of chickens with lactobacilli influences elicitation of immune responses. Clin. Vaccine Immunol. 18, 1447-1455 (2011)

32. Brisbin, J. T., Gong, J., Parvizi, P. \& Sharif, S. Effects of lactobacilli on cytokine expression by chicken spleen and cecal tonsil cells. Clin. Vaccine Immunol. 17, 1337-1343 (2010).

33. Noujaim, J. C. et al. Detection of T lymphocytes in intestine of broiler chicks treated with Lactobacillus spp. and challenged with Salmonella enterica serovar enteritidis. Poult. Sci. 87, 927-933 (2008).

34. Valladares, R. et al. Lactobacillus johnsonii inhibits indoleamine 2,3-dioxygenase and alters tryptophan metabolite levels in BioBreeding rats. FASEB J. 27, 1711-1720 (2013).

35. Marin, I. A. et al. Microbiota alteration is associated with the development of stress-induced despair behavior. Sci. Rep. 7, 1-10 (2017).

36. Gummalla, S. \& Broadbent, J. R. Tyrosine and phenylalanine catabolism by Lactobacillus cheese flavor adjuncts. J. Dairy Sci. 84, 1011-1019 (2001).

37. Dhaliwal, J. et al. Lactobacillus plantarum MTCC 9510 supplementation protects from chronic unpredictable and sleep deprivation-induced behaviour, biochemical and selected gut microbial aberrations in mice. J. Appl. Microbiol. 125, 257-269 (2018).

38. Barrett, E., Ross, R. P., O’Toole, P. W., Fitzgerald, G. F. \& Stanton, C. $\gamma$-Aminobutyric acid production by culturable bacteria from the human intestine. J. Appl. Microbiol. 113, 411-417 (2012).

39. Liu, W. H. et al. Alteration of behavior and monoamine levels attributable to Lactobacillus plantarum PS128 in germ-free mice. Behav. Brain Res. 298, 202-209 (2016).

40. Oleskin, A. V. et al. Lactic-acid bacteria supplement fermented dairy products with human behavior-modifying neuroactive compounds. J. Pharm. Nutr. Sci. 4, 199-206 (2014).

41. Girvin, G. T. \& Stevenson, J. W. Cell free 'Choline Acetylase’ from Lactobacillus plantarum. Can. J. Biochem. Physiol. 32, 131-146 (1954).

42. Rowatt, E. The relation of pantothenic acid to acetylcholine formation by a strain of Lactobacillus plantarum. J. Gen. Microbiol. 2, 25-30 (1948).

43. Leblhuber, F. et al. The immunopathogenesis of Alzheimer's disease is related to the composition of gut microbiota. Nutrients https://doi.org/10.3390/nu13020361 (2021).

44. Reader, B. F. et al. Peripheral and central effects of repeated social defeat stress: Monocyte trafficking, microglial activation, and anxiety. Neuroscience 289, 429-442 (2015).

45. Toben, C. \& Baune, B. T. An act of balance between adaptive and maladaptive immunity in depression: A role for T lymphocytes. J. Neuroimmune Pharmacol. 10, 595-609 (2015).

46. Strasser, B., Sperner-Unterweger, B., Fuchs, D. \& Gostner, J. M. Mechanisms of inflammation-associated depression: Immune influences on tryptophan and phenylalanine metabolisms. Curr. Top. Behav. Neurosci. 31, 95-116 (2017).

47. Hüfner, K., Fuchs, D., Blauth, M. \& Sperner-Unterweger, B. How acute and chronic physical disease may influence mental health: An Analysis of neurotransmitter precursor amino acid levels. Psychoneuroendocrinology 106, 95-101 (2019).

48. McVey Neufeld, K.-A., Kay, S. \& Bienenstock, J. Mouse strain affects behavioral and neuroendocrine stress responses following administration of probiotic Lactobacillus rhamnosus JB-1 or traditional antidepressant fluoxetine. Front. Neurosci. 12, 1-7 (2018).

49. Meyer, B., Bessei, A. W., Vahjen, W., Zentek, J. \& Harlander-Matauschek, A. Dietary inclusion of feathers affects intestinal microbiota and microbial metabolites in growing leghorn-type chickens. Poult. Sci. 91, 1506-1513 (2012).

50. Birkl, P. et al. Differences in cecal microbiome of selected high and low feather-pecking laying hens. Poult. Sci. 97, 3009-3014 (2018).

51. van der Eijk, J. A. J. et al. Differences in gut microbiota composition of laying hen lines divergently selected on feather pecking. Poult. Sci. 98, 1-13 (2019).

52. Kjaer, J. B. Feather pecking in domestic fowl is genetically related to locomotor activity levels: Implications for a hyperactivity disorder model of feather pecking. Behav. Genet. 39, 564-570 (2009). 
53. Van Hierden, Y. M., De Boer, S. F., Koolhaas, J. M. \& Korte, S. M. The control of feather pecking by serotonin. Behav. Neurosci. 118, 575-583 (2004).

54. van Staaveren, N. \& Harlander, A. Cause and prevention of injurious pecking in chickens. In Understanding the Behaviour and Improving the Welfare of Chickens (ed. Nicol, C.) (Burleigh Dodds Series in Agricultural Science, 2020).

55. Iffland, H. et al. A novel model to explain extreme feather pecking behavior in laying hens. Behav. Genet. https://doi.org/10. 1007/s10519-019-09971-w (2019).

56. Kjaer, J. B. \& Sørensen, P. Feather pecking behaviour in White Leghorns, a genetic study. Br. Poult. Sci. 38, 333-341 (1997).

57. Kjaer, J. B., Sørensen, P. \& Su, G. Divergent selection on feather pecking behaviour in laying hens (Gallus gallus domesticus). Appl. Anim. Behav. Sci. 71, 229-239 (2001).

58. Blokhuis, H. J. Feather-pecking in poultry: Its relation with ground-pecking. Appl. Anim. Behav. Sci. 16, 63-67 (1986).

59. Wennrich, G. Ethological studies of different domestic chicken (Gallus domesticus) hybrids in confined floor management with special reference to aggressive behaviour as well as feather picking and cannibalism. 1st Communication: Pecking movements in feeding behaviour. Arch. Gefluegelkd. 38, 143-149 (1974).

60. Brunberg, E. I. et al. Omnivores going astray: A review and new synthesis of abnormal behavior in pigs and laying hens. Front. Vet. Sci. 3, 1-15 (2016).

61. Van Hierden, Y. M. et al. Adrenocortical reactivity and central serotonin and dopamine turnover in young chicks from a high and low feather-pecking line of laying hens. Physiol. Behav. 75, 653-659 (2002).

62. Kops, M. S. et al. Brain monoamine levels and behaviour of young and adult chickens genetically selected on feather pecking. Behav. Brain Res. 327, 11-20 (2017).

63. Birkl, P. et al. The role of tryptophan-kynurenine in feather pecking in domestic chicken lines. Front. Vet. Sci. 6, 209 (2019).

64. Birkl, P., Franke, L., Rodenburg, T. B., Ellen, E. \& Harlander-Matauschek, A. A role for plasma aromatic amino acids in injurious pecking behavior in laying hens. Physiol. Behav. 175, 88-96 (2017).

65. Buitenhuis, A. J. et al. Genetic and phenotypic correlations between feather pecking behavior, stress response, immune response, and egg quality traits in laying hens. Poult. Sci. 83, 1077-1082 (2004).

66. Buitenhuis, A. J., Kjaer, J. B., Labouriau, R. \& Juul-Madsen, H. R. Altered circulating levels of serotonin and immunological changes in laying hens divergently selected for feather pecking behavior. Poult. Sci. 85, 1722-1728 (2006).

67. Flisikowski, K. et al. Variation in neighbouring genes of the dopaminergic and serotonergic systems affects feather pecking behaviour of laying hens. Anim. Genet. 40, 192-199 (2009).

68. Biscarini, F. et al. Across-line SNP association study for direct and associative effects on feather damage in laying hens. Behav. Genet. 40, 715-727 (2010).

69. Brunberg, E., Jensen, P., Isaksson, A. \& Keeling, L. Feather pecking behavior in laying hens: Hypothalamic gene expression in birds performing and receiving pecks. Poult. Sci. 90, 1145-1152 (2011).

70. Wysocki, M., Bessei, W., Kjaer, J. B. \& Bennewitz, J. Genetic and physiological factors influencing feather pecking in chickens. World's Poult. Sci. J. 66, 659-672 (2010).

71. Borda-Molina, D. et al. Gut microbial composition and predicted functions are not associated with feather pecking and antagonistic behavior in laying hens. Life 11, 235 (2021).

72. Bharwani, A., Mian, M. F., Surette, M. G., Bienenstock, J. \& Forsythe, P. Oral treatment with Lactobacillus rhamnosus attenuates behavioural deficits and immune changes in chronic social stress. BMC Med. 15, 1-14 (2017).

73. Mindus, C. et al. Ingestion of Lactobacillus rhamnosus modulates chronic stress-induced feather pecking in chickens. Sci. Rep. https://doi.org/10.1038/s41598-021-96615-x (2021).

74. Lafuse, W. P. et al. Exposure to a social stressor induces translocation of commensal lactobacilli to the spleen and priming of the innate immune system. J. Immunol. 198, 2383-2393 (2017).

75. Madsen, K. et al. Probiotic bacteria enhance murine and human intestinal epithelial barrier function. Gastroenterology 121, 580-591 (2001).

76. Forsythe, P., Inman, M. D. \& Bienenstock, J. Oral treatment with live Lactobacillus reuteri inhibits the allergic airway response in mice. Am. J. Respir. Crit. Care Med. 175, 561-569 (2007).

77. Karimi, K., Inman, M. D., Bienenstock, J. \& Forsythe, P. Lactobacillus reuteri-induced regulatory T cells protect against an allergic airway response in mice. Am. J. Respir. Crit. Care Med. 179, 186-193 (2009).

78. Kjaer, J. B. \& Guémené, D. Adrenal reactivity in lines of domestic fowl selected on feather pecking behavior. Physiol. Behav. 96, 370-373 (2009).

79. Kops, M. S. et al. Effects of feather pecking phenotype (severe feather peckers, victims and non-peckers) on serotonergic and dopaminergic activity in four brain areas of laying hens (Gallus gallus domesticus). Physiol. Behav. 120, 77-82 (2013).

80. Fernstrom, J. D. \& Fernstrom, M. H. Tyrosine, phenylalanine, and catecholamine synthesis and function in the brain. J. Nutr. 137,1539 S-1547S (2007).

81. Wurtman, R. J., Hefti, F. \& Melamed, E. Precursor control of neurotransmitter synthesis. Pharmacol. Rev. 32, 315-335 (1980).

82. Fernstrom, J. D. \& Wurtman, R. J. Brain serotonin content: Physiological regulation by plasma neutral amino acids. Science 178, 414-416 (1972).

83. McAdie, T. M. \& Keeling, L. J. The social transmission of feather pecking in laying hens: Effects of environment and age. Appl. Anim. Behav. Sci. 75, 147-159 (2002).

84. Decina, C. et al. An investigation of associations between management and feather damage in Canadian laying hens housed in furnished cages. Animals 9, 135 (2019).

85. Savory, C. J. \& Mann, J. S. Behavioural development in groups of pen-housed pullets in relation to genetic strain, age and food form. Br. Poult. Sci. 38, 38-47 (1997).

86. van der Eijk, J. A. J., Lammers, A., Li, P., Kjaer, J. B. \& Rodenburg, T. B. Feather pecking genotype and phenotype affect behavioural responses of laying hens. Appl. Anim. Behav. Sci. 205, 141-150 (2018).

87. van der Eijk, J. A. J. et al. Early-life microbiota transplantation affects behavioural responses, serotonin and immune characteristics in chicken lines divergently selected on feather pecking. Sci. Rep. 10, 1-13 (2020).

88. Cronin, G. M. et al. Why did severe feather pecking and cannibalism outbreaks occur? An unintended case study while investigating the effects of forage and stress on pullets during rearing. Poult. Sci. 97, 1484-1502 (2018).

89. van Staaveren, N., Ellis, J., Baes, C. F. \& Harlander-Matauschek, A. A meta-analysis on the effect of environmental enrichment on feather pecking and feather damage in laying hens. Poult. Sci. https://doi.org/10.1016/j.psj.2020.11.006 (2020).

90. Widowski, T. \& Torrey, S. Rearing young birds for adaptability. In Advances in Poultry Welfare (ed. Mench, J. A.) 49-76 (Woodhead Publishing, 2018).

91. Cheng, H. W., Singleton, P. \& Muir, W. M. Social stress in laying hens: Differential dopamine and corticosterone responses after intermingling different genetic strains of chickens. Poult. Sci. 81, 1265-1272 (2002).

92. Mwangi, W. N. et al. Regional and global changes in TCRalphabeta T cell repertoires in the gut are dependent upon the complexity of the enteric microflora. Dev. Comp. Immunol. 34(4), 406-417. https://doi.org/10.1016/j.dci.2009.11.009 (2010).

93. Perez-Burgos, A. et al. Psychoactive bacteria Lactobacillus rhamnosus (JB-1) elicits rapid frequency facilitation in vagal afferents. Am. J. Physiol. 304, 211-220 (2013).

94. Cervantes-Barragan, L. et al. Lactobacillus reuteri induces gut intraepithelial CD4+CD8aa+ T cells. Science 357, 806-810 (2017). 
95. Jang, S.-O. et al. Asthma Prevention by Lactobacillus rhamnosus in a mouse model is associated with CD4+CD25+ Foxp3+ T cells. Allergy Asthma Immunol Res. 4, 150-156 (2012).

96. Karimi, K., Kandiah, N., Chau, J., Bienenstock, J. \& Forsythe, P. A Lactobacillus rhamnosus strain induces a heme oxygenase dependent increase in Foxp3+ regulatory T cells. PLoS ONE 7, 1-12 (2012).

97. Yi, H. et al. Integrated metabolomic and proteomics profiling reveals the promotion of: Lactobacillus reuteri LR1 on amino acid metabolism in the gut-liver axis of weaned pigs. Food Funct. 10, 7387-7396 (2019).

98. Chen, H. et al. Lactobacillus plantarum consumption increases PepT1-mediated amino acid absorption by enhancing protein kinase C Activity in spontaneously colitic mice. J. Nutr. 140, 2201-2206 (2010).

99. Yuasa, H. J., Mizuno, K. \& Ball, H. J. Low efficiency IDO2 enzymes are conserved in lower vertebrates, whereas higher efficiency IDO1 enzymes are dispensable. FEBS J. 282, 2735-2745 (2015).

100. Ball, H. J. et al. Characterization of an indoleamine 2,3-dioxygenase-like protein found in humans and mice. Gene 396, 203-213 (2007).

101. Fuchs, D. et al. Increased endogenous interferon-gamma and neopterin correlate with increased degradation of tryptophan in human immunodeficiency virus type 1 infection. Immunol. Lett. 28, 207-211 (1991).

102. Neurauter, G. et al. Chronic immune stimulation correlates with reduced phenylalanine turnover. Curr. Drug Metab. 9, 622-627 (2008).

103. Sperner-Unterweger, B., Kohl, C. \& Fuchs, D. Immune changes and neurotransmitters: Possible interactions in depression?. Prog. Neuro-Psychopharmacol. Biol. Psychiatry 48, 268-276 (2014).

104. Leblhuber, F., Steiner, K., Schuetz, B., Fuchs, D. \& Gostner, J. M. Probiotic supplementation in patients with Alzheimer's dementia: An explorative intervention study. Curr. Alzheimer Res. 15, 1106-1113 (2018).

105. Gostner, J. M. et al. Tryptophan metabolism and related pathways in psychoneuroimmunology: The impact of nutrition and lifestyle. Neuropsychobiology 79, 89-99 (2020).

106. Bender, D. A. Biochemistry of tryptophan in health and disease. Mol. Aspects Med. 6, 101-197 (1983).

107. van der Eijk, J. A. J., Lammers, A., Kjaer, J. B. \& Rodenburg, T. B. Stress response, peripheral serotonin and natural antibodies in feather pecking genotypes and phenotypes and their relation with coping style. Physiol. Behav. 199, 1-10 (2019).

108. Wu, H., Gong, J. \& Liu, Y. Indoleamine 2, 3-dioxygenase regulation of immune response (Review). Mol. Med. Rep. 17, 4867-4873 (2018).

109. Dennis, R. L. \& Cheng, H. W. The dopaminergic system and aggression in laying hens. Poult. Sci. 90, 2440-2448 (2011).

110. Van Hierden, Y. M., Koolhaas, J. M. \& Korte, S. M. M. Chronic increase of dietary L-tryptophan decreases gentle feather pecking behaviour. Appl. Anim. Behav. Sci. 89, 71-84 (2004).

111. Birkl, P. et al. Effects of acute tryptophan depletion on repetitive behavior in laying hens. Front. Vet. Sci. 6, 230 (2019).

112. Savory, C. J., Mann, J. S. \& Macleod, M. G. Incidence of pecking damage in growing bantams in relation to food form, group size, stocking density, dietary tryptophan concentration and dietary protein source. Br. Poult. Sci. 40, 579-584 (1999).

113. Bolhuis, J. E. et al. Effects of genetic group selection against mortality on behavior and peripheral serotonin in domestic laying hens with trimmed and intact beaks. Physiol. Behav. 97, 470-475 (2009).

114. Le Roy, C. I., Woodward, M. J., Ellis, R. J., La Ragione, R. M. \& Claus, S. P. Antibiotic treatment triggers gut dysbiosis and modulates metabolism in a chicken model of gastro-intestinal infection. BMC Vet. Res. 15, 37 (2019).

115. Simon, K. et al. Long-term effects of early life microbiota disturbance on adaptive immunity in laying hens. Poult. Sci. 95, 1543-1554 (2016).

116. Danielsen, M. \& Wind, A. Susceptibility of Lactobacillus spp. to antimicrobial agents. Int. J. Food Microbiol. 82, 1-11 (2003).

117. Lonkar, P., Harne, S. D., Kalorey, D. R. \& Kurkure, N. V. Isolation, in vitro antibacterial activity, bacterial sensitivity and plasmid profile of lactobacilli. Asian-Australasian J. Anim. Sci. 18, 1336-1342 (2005).

118. Dec, M., Urban-Chmiel, R., Stẹpień-Pyśniak, D. \& Wernicki, A. Assessment of antibiotic susceptibility in Lactobacillus isolates from chickens. Gut Pathog. 9, 1-16 (2017).

119. Percie du Sert, N. et al. The ARRIVE guidelines 2.0: Updated guidelines for reporting animal research. PLOS Biol. 18, e3000410 (2020).

120. Huber-Eicher, B., Audige, L. \& Audigé, L. Analysis of risk factors for the occurrence of feather pecking in laying hen growers. Br. Poult. Sci. 40, 599-604 (1999).

121. Decina, C., Berke, O., van Staaveren, N., Baes, C. F. \& Harlander-Matauscheck, A. Development of a scoring system to assess feather damage in Canadian laying hen flocks. Animals 9, 436 (2019).

\section{Acknowledgements}

We would like to thank the personnel at the University of Guelph's Research Station for the technical assistance and maintenance of the birds. We also would like to acknowledge Dr. Michelle Edwards for her help in statistical analysis and all the other students for their assistance with data collection and analysis of the videos. This work was supported by the Natural Sciences and Engineering Research Council of Canada (NSERC) - Discovery Grant number 400983, the Ontario Ministry of Agriculture, Food and Rural Affairs (OMAFRA), grant number 27267 and 2015-2384, and Egg Farmers of Canada. The funders had no role in the design of the study; in the collection, analyses, or interpretation of data; in the writing of the manuscript, and in the decision to publish the results.

\section{Author contributions}

C.M., N.v.S., W.K., P.F. and A.H.-M. conceived and designed the experiment. W.K., P.F. and A.H.-M. secured the funding for the experiment. C.M. and N.v.S. performed the experiment and collected the data at the research station. D.F., J.M.G. and M.F.M. processed the samples. C.M. conducted the statistical analysis. C.M. wrote the original draft. C.M., N.v.S., D.F., J.M.G., J.B.K., W.K., M.F.M., A.K.S., P.F. and A.H.-M. reviewed and approved the final manuscript before submission.

\section{Competing interests}

The authors declare no competing interests.

\section{Additional information}

Supplementary Information The online version contains supplementary material available at https://doi.org/ 10.1038/s41598-021-98459-x.

Correspondence and requests for materials should be addressed to A.H.-M.

Reprints and permissions information is available at www.nature.com/reprints. 
Publisher's note Springer Nature remains neutral with regard to jurisdictional claims in published maps and institutional affiliations.

(c) (i) Open Access This article is licensed under a Creative Commons Attribution 4.0 International License, which permits use, sharing, adaptation, distribution and reproduction in any medium or format, as long as you give appropriate credit to the original author(s) and the source, provide a link to the Creative Commons licence, and indicate if changes were made. The images or other third party material in this article are included in the article's Creative Commons licence, unless indicated otherwise in a credit line to the material. If material is not included in the article's Creative Commons licence and your intended use is not permitted by statutory regulation or exceeds the permitted use, you will need to obtain permission directly from the copyright holder. To view a copy of this licence, visit http://creativecommons.org/licenses/by/4.0/.

(C) The Author(s) 2021 